$$
\begin{aligned}
& \text { تنمية الرافدين العدد عq مجلد اب لسنة q ... } \\
& \text { ص ص[0] } \\
& \text { كلية الإدارة والاقتصاد -جامعة الموصل } \\
& \text { تفسيرات سلو ك القطيع وأثرها في حر كية الاستثمار } \\
& \text { الدكتور حسن صبحي حسن العباس } \\
& \text { مدرس -كلية الحدباء الجامعة } \\
& \text { hassn_subhee@yahoo.com }
\end{aligned}
$$

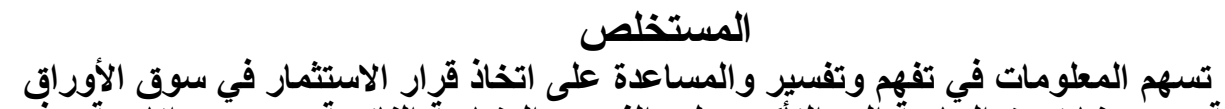

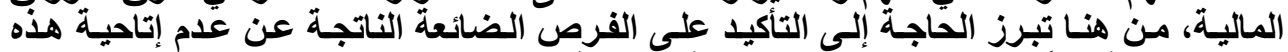

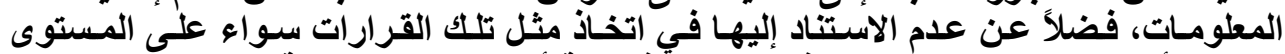

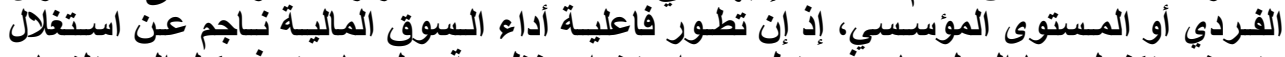

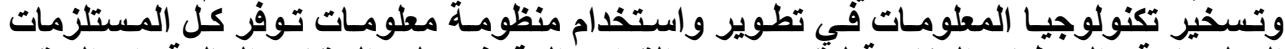

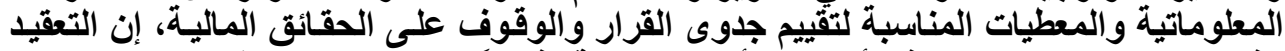

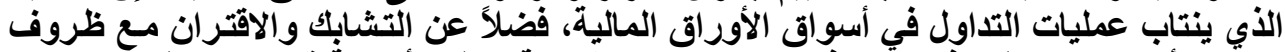

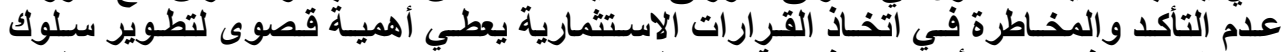

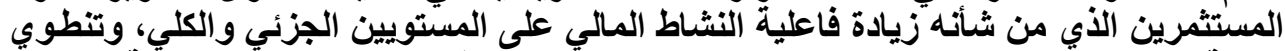

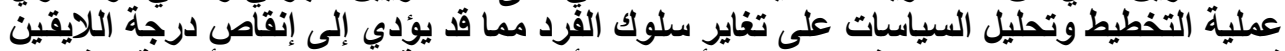

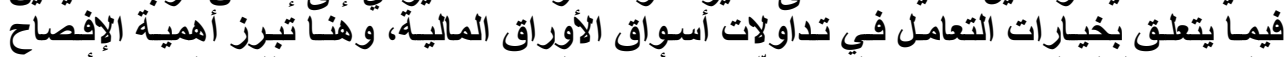

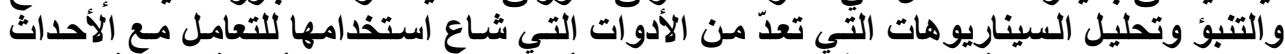

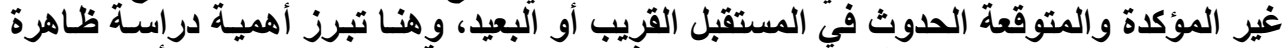

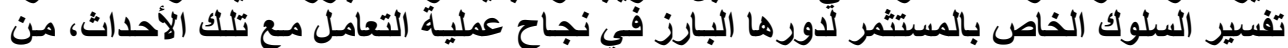

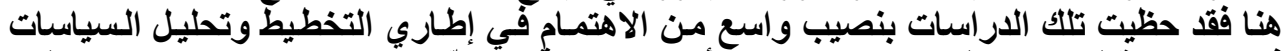

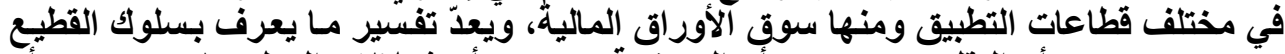

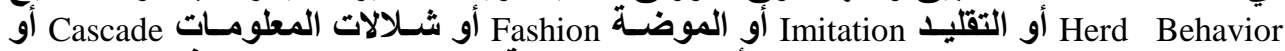

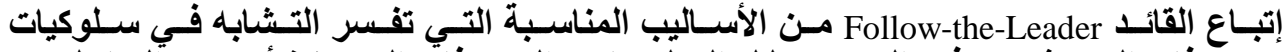

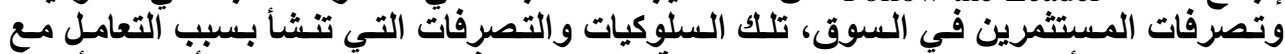

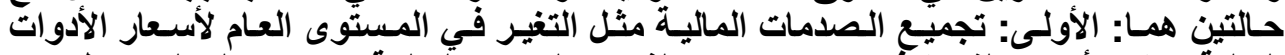

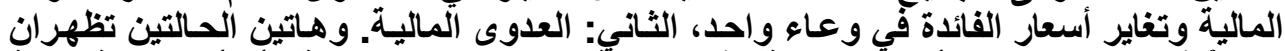

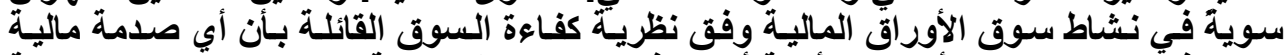

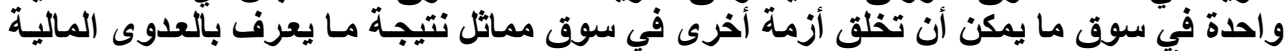

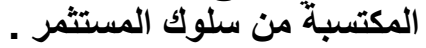

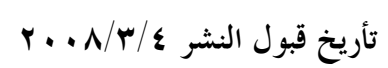

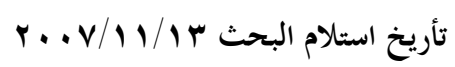




\title{
The Interpretations of Cattle Behaviors and their Impact on Investment Mobility in Stock Markets
}

\author{
Maan W. Al-Maadhaeedi (PhD) \\ Assistant Professor \\ Department of Business Administration \\ University of Mosul
}

\author{
Hasan S. Al-Abbas (PhD) \\ Lecturer \\ Al-Hadbaa University College \\ Mosul
}

\begin{abstract}
The importance of data in understanding and interpreting as well as aid to make the decision has become a decisive matter. So, concentration should be directed towards the wasted chances of losing data and no - reliance on in decision - making process almost on the individual level or total once. The upgrade of economic performance has resulted of using data and IT in developing the information systems to assess the result of decisions and facts. The progress in economic society, the association of uncertainty conditions and risk in decision making process yield a crucial importance to upgrade the investors' behavior that may increase the activity of economy partially and totally. Planning and policy analysis draw upon the variance in the individual behavior, this may lead to decrease of disbelief regarding the choices of financial markets dealings. Disclosure, broadcasting and scenario analysis are sorts of widespread tools used to treat the uncertain events and expected as well in the next future or more. Finally, the phenomenon of private behavior of the investor has widely tackled in planning and policy analysis in various applicable sectors such as financial market. The concept of Herd Behavior or Imitation or Fashion or Cascade or Follow-the-Leader is demonstrated as a sort of financial markets. This concept is however similar to the behavior and manner of investors inside the market. This sort of behavior may emerge as a result of two principles; first the range of collecting the financial setback such as the change in the general level of financial prices and the change in the prices of interest. Second; it depends on financial contagion, these two concepts seek in the market activity that any market setback may create a crisis in the same market as a result of acquired financial contagion of the investor's behavior.
\end{abstract}

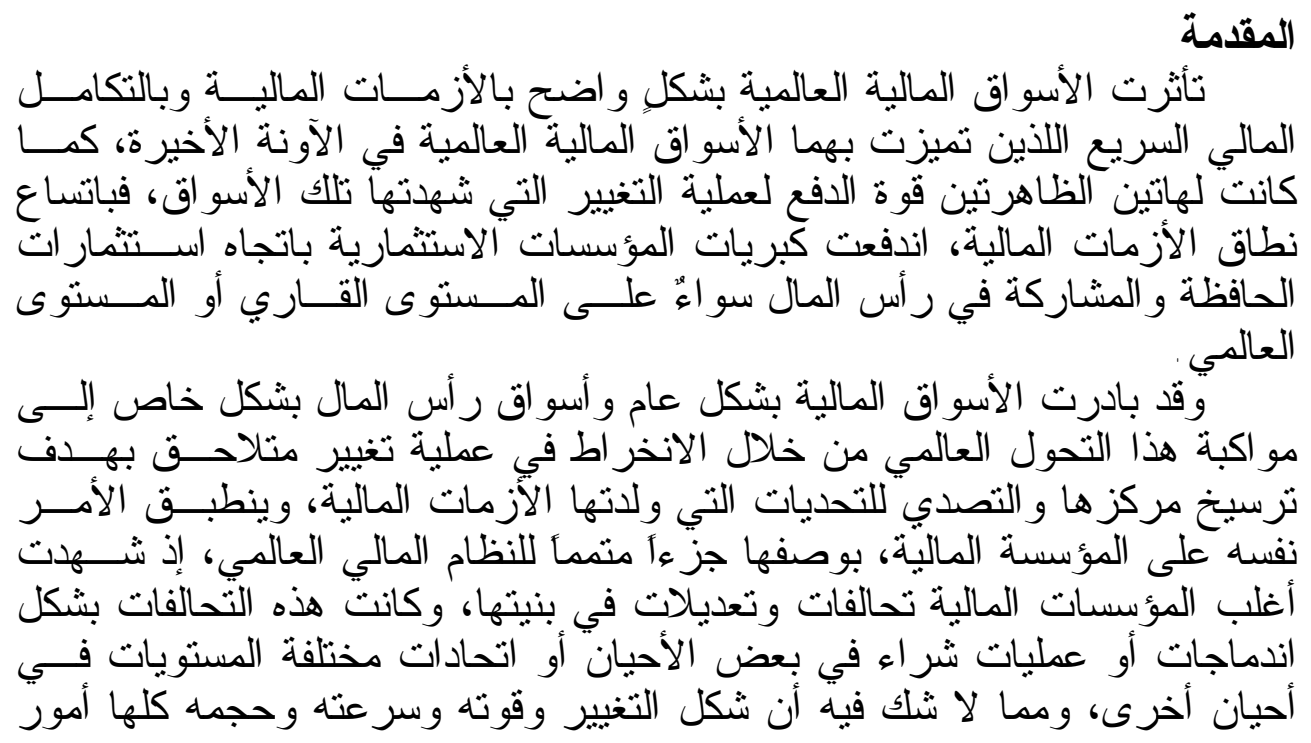


تعكس مستوى التقام و التتظيم الذي تلتمتع به أسواق الأور اق الماليــة مــن جهـــة

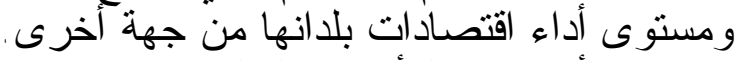

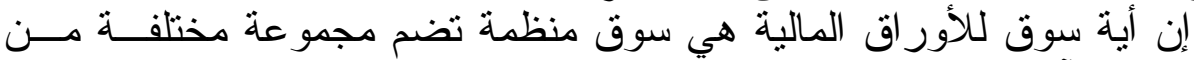

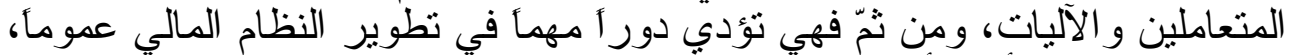

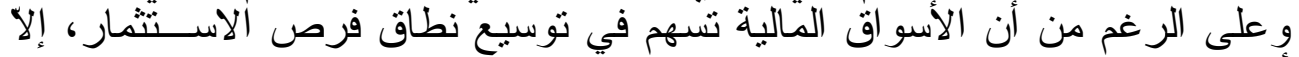

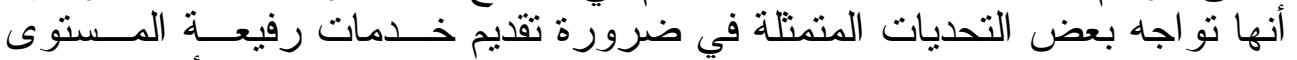

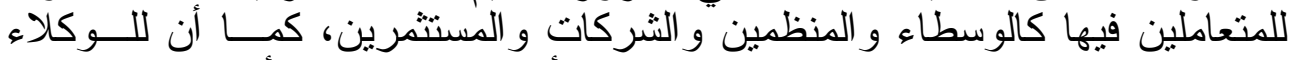

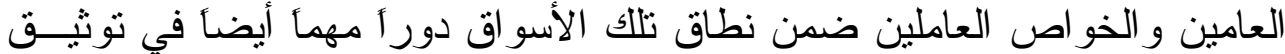

الصلة القائمة بينها.

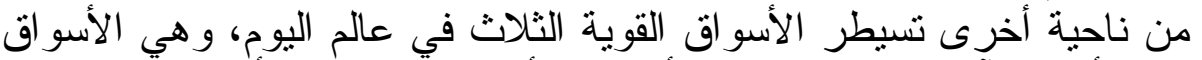

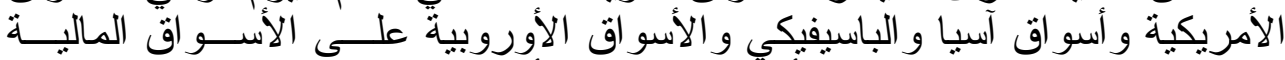

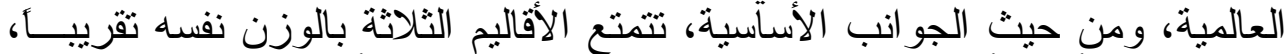

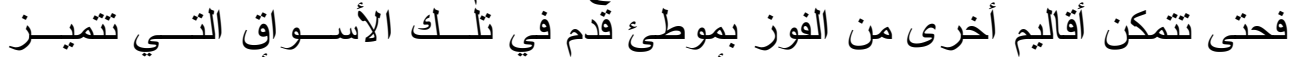

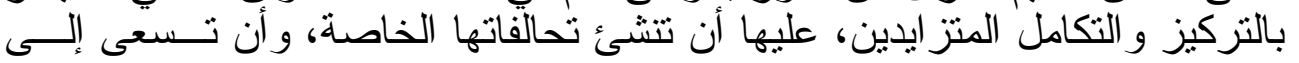
توثيق التعاون فيما بينها.

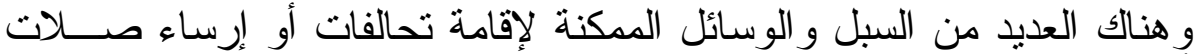

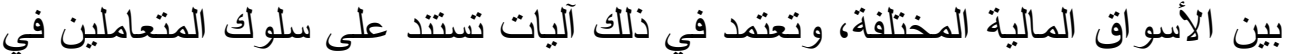

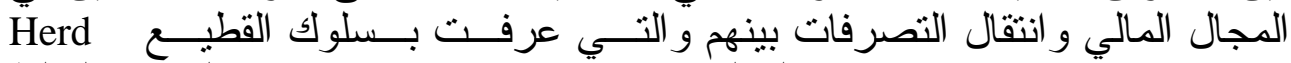
Behavior Financial Contagion

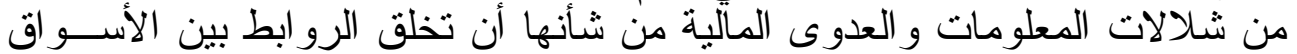

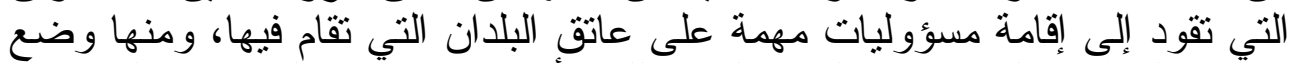

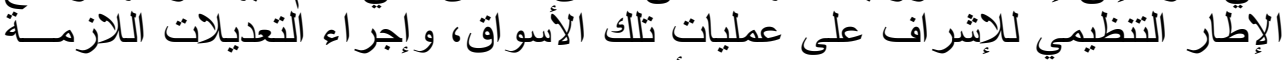

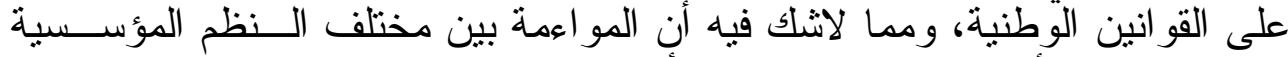
و القانونية من شأنه ترسيخ مركز تلالك الأسو اق في البلدان ذات التحالفات و المشاركة

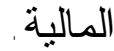

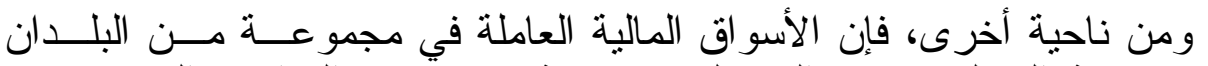

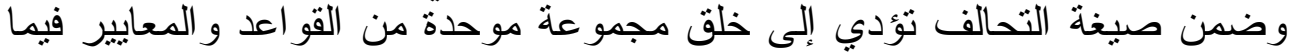

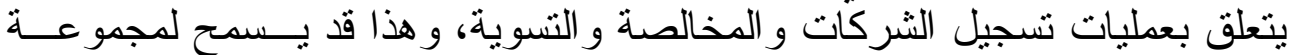

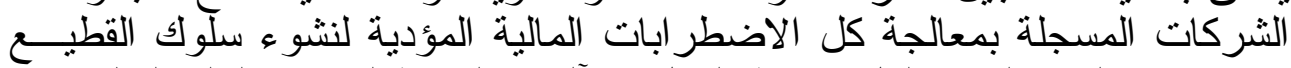

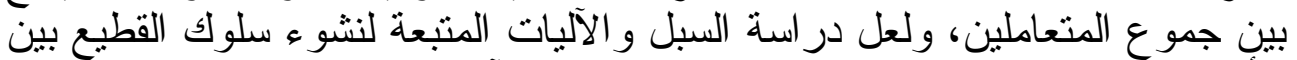

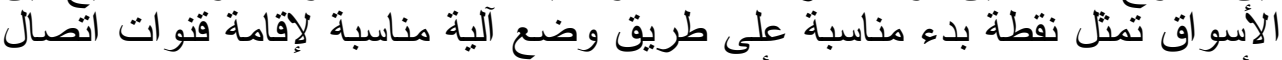
للأور اق المالية وغرفة مقاصة للأسهم و السندات.

نتبثق أهمية البحث من كونه نتاول موضو عأ حيويأ برنبط بما يعرف بالسلوك

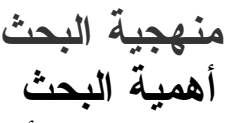

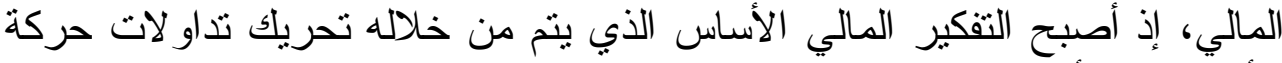

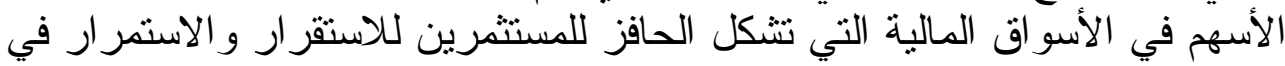




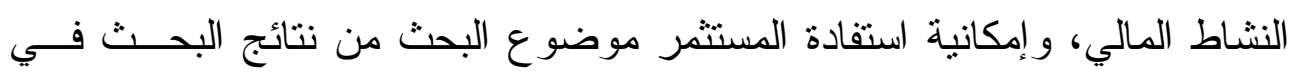

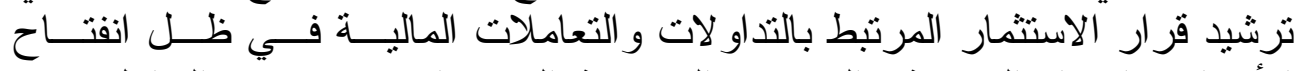

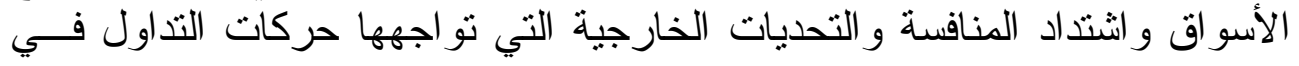

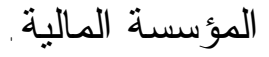

وبقي هذا الموضو ع غائباً في بعديه المعرفي و الميداني عن المؤسسة الماليــــة

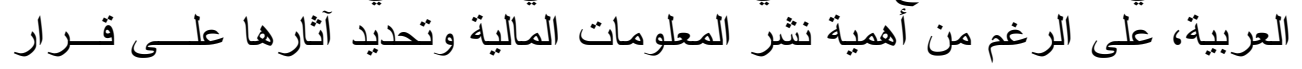

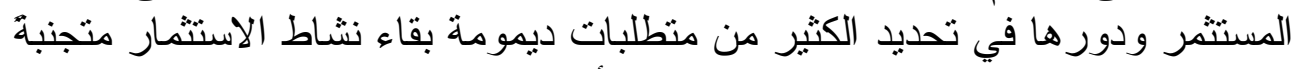

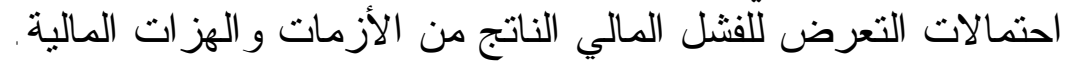

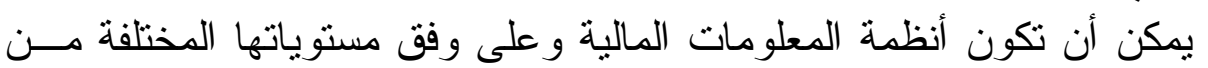

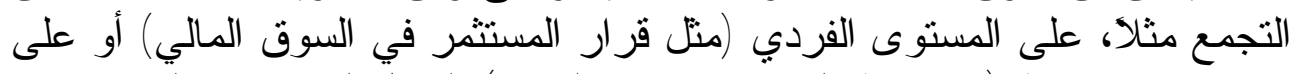

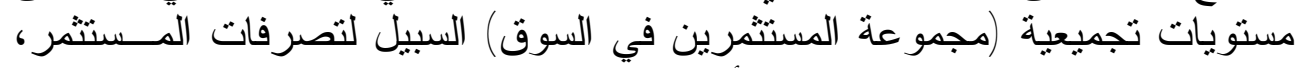

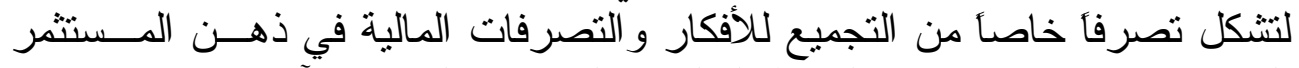

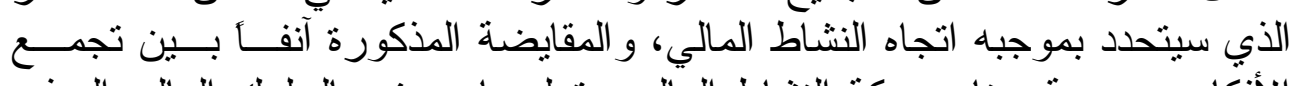

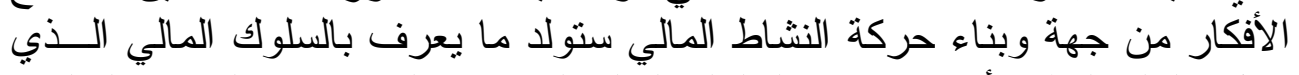

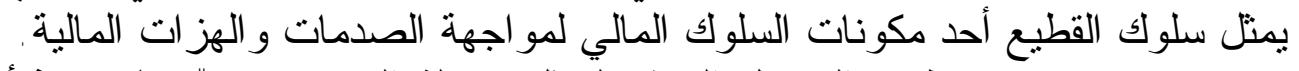

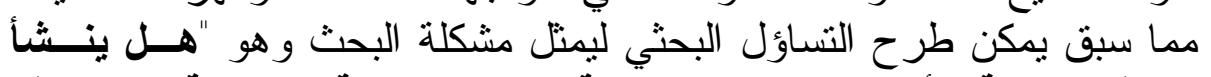

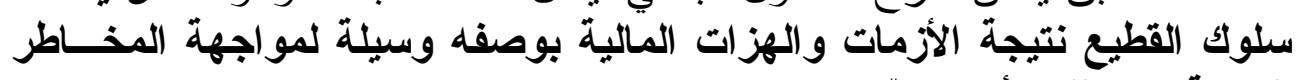

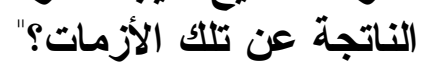

فروض البحث • ثؤثر شلالات المعلومات على حالتي البيع و الثر اء للمحافظ الاستثمارية العاملـــة

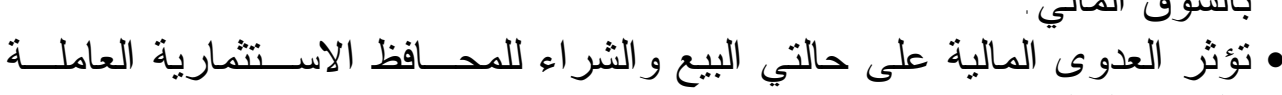

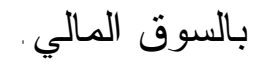

تتسم الدول النامية ومنها الدول العربية بنقص شديد في تو افر البيانات التــي

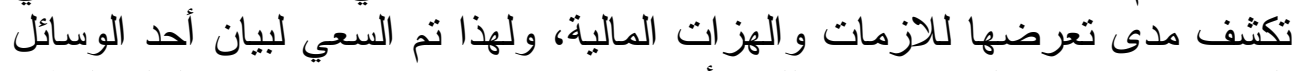

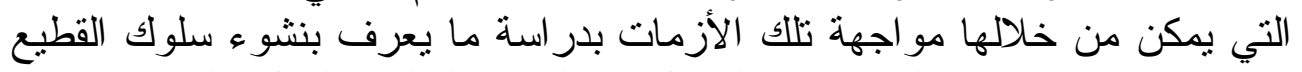

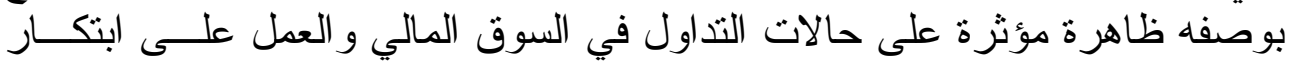

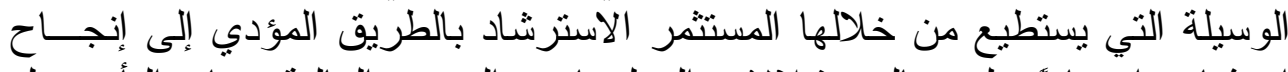

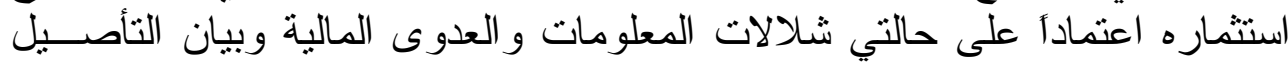
النظري و التقني لهاتين الحالتين بالبحث و التطبيق . 
تم الاعتماد على عينة من المحافظ المتداولة في سوق السعودية المالية وهي:

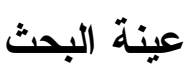
1. ا ـ محفظة استثمار صندوق أمريكا الثمالية. r r r محفة استثمار صندوق صنفة الأسهم الأمريكية.

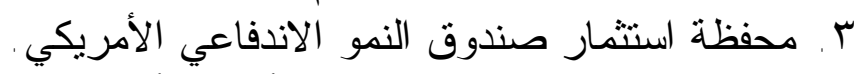
ع ـ محفظة استثمار صندوق مؤشر الأسهم الأمريكية.

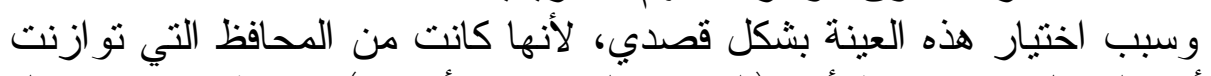

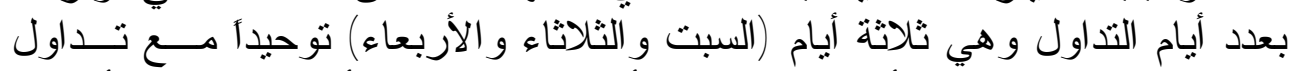

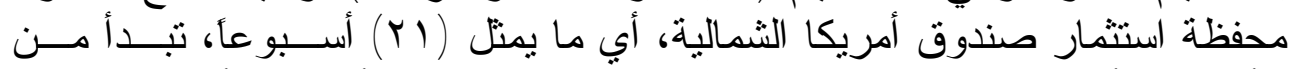

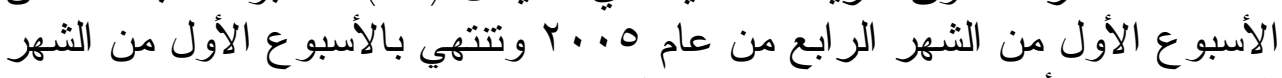

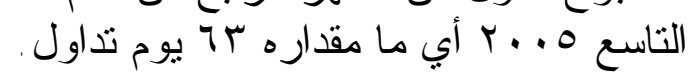

أثر الوفرة المعلوماتية في نشاط الأسواق المالية

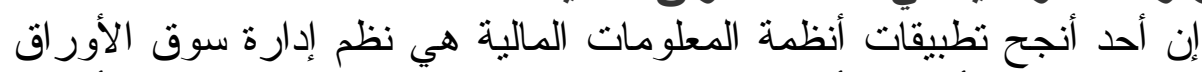

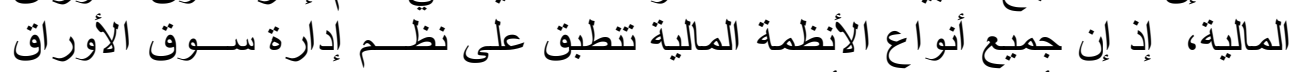

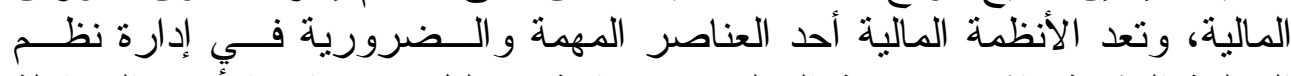

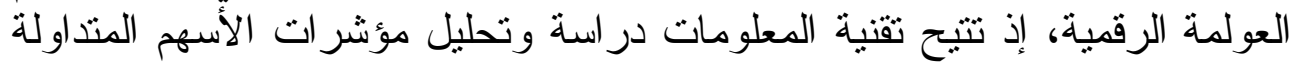

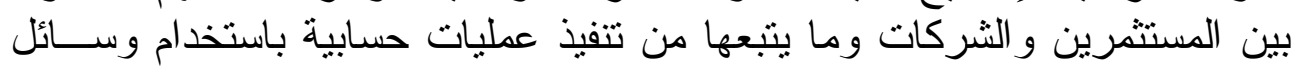

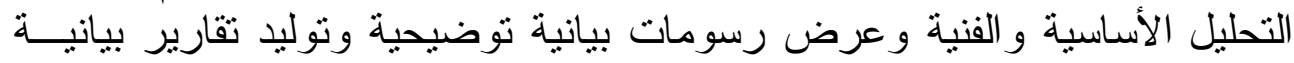

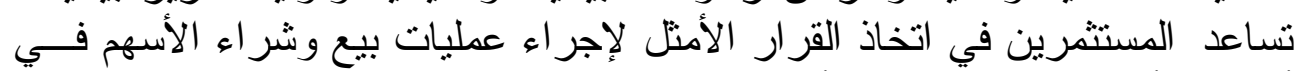

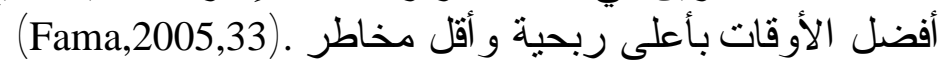

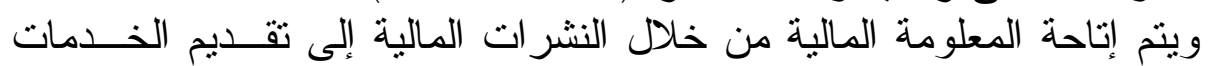

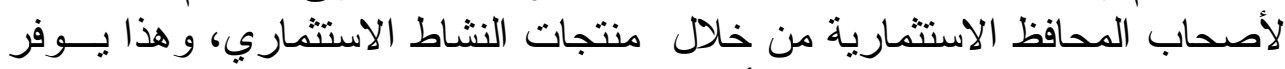

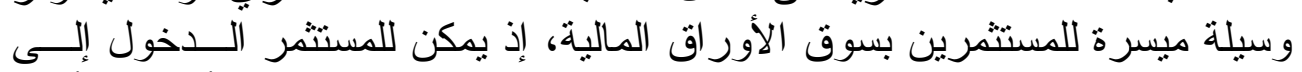

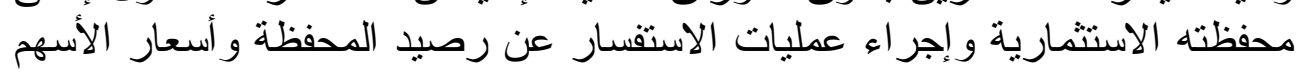

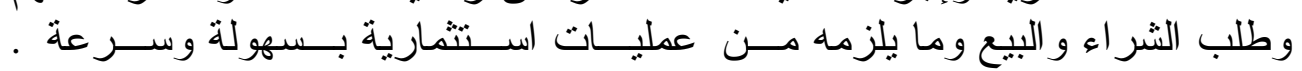
(Ioannides,2003,12)

ويستقيد من إتاحية المعلومة المالية تقديم خدمات لمدراء المحافظ الاستثمارية

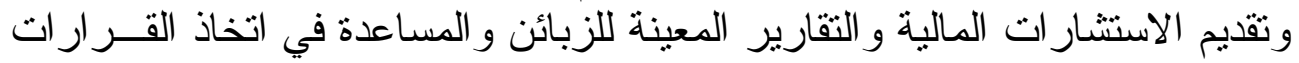

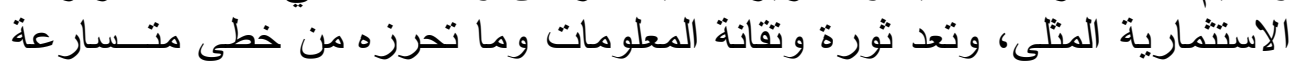

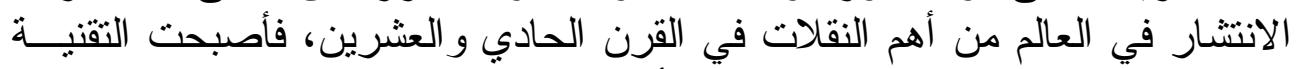

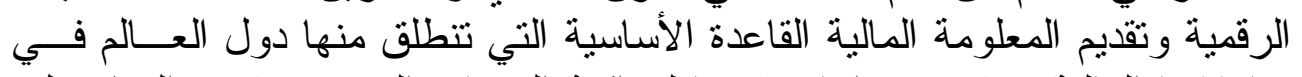

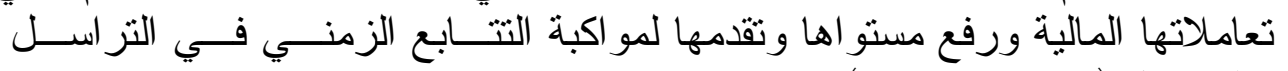
و التو اصل (Fama,2005,53). 


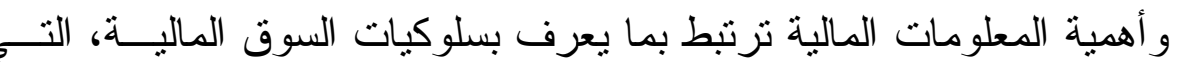

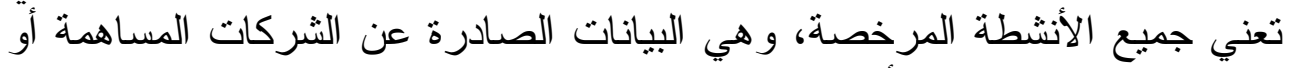

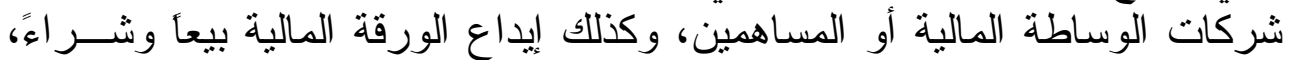
وقد صدرت اللائحة التنفيذية المتعلقة بسلوكيات السوق المالية عن طريــق عـدة المدة

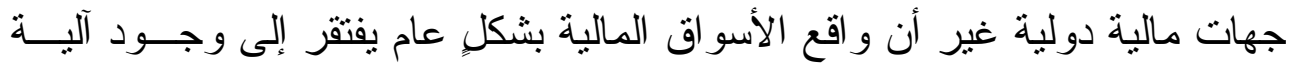

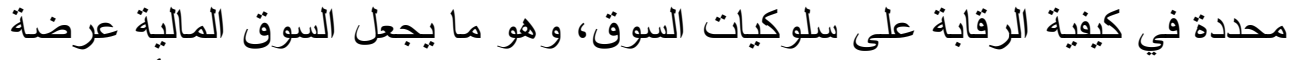

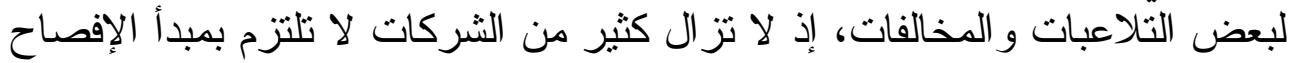

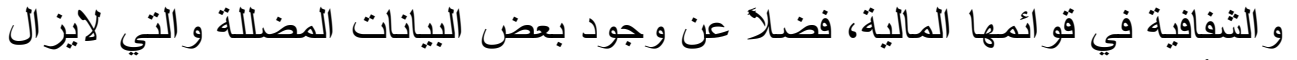
لها تأثير قوي في السوق لاسيما من كبار المضاربين، و هذا يجعل هيئة سوق المات المال

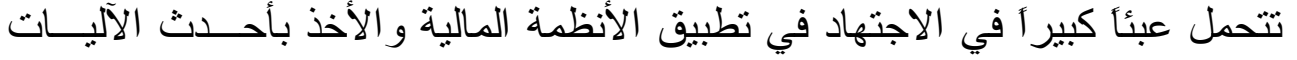

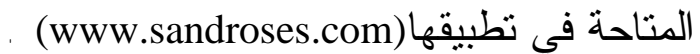
وتبقى أهم العو امل الأساسية التي تؤدي إلى عدم الاستقرار المالي و الإســـهام

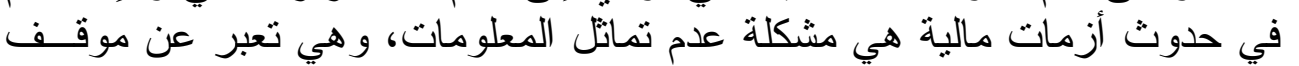

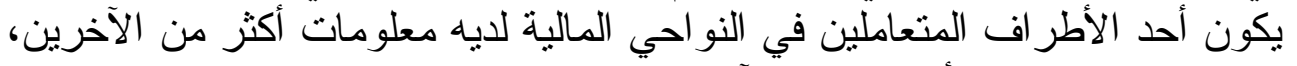
مما ينزتب على ذلك أن الطرف الآخر لن يستطيع تقييم المخاطر بشكل سليم وينتج

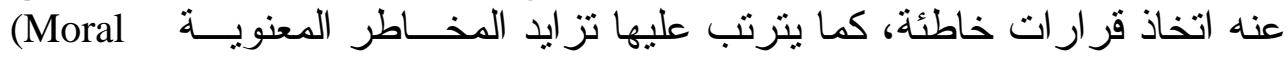

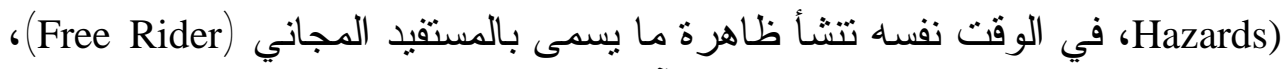

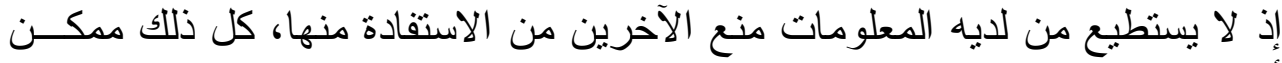

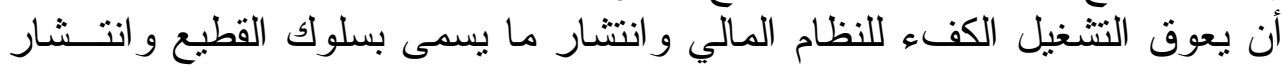
العدوى أو تفشيها (سريان الإشاعات) (Devenow\&Welch.2000,6).

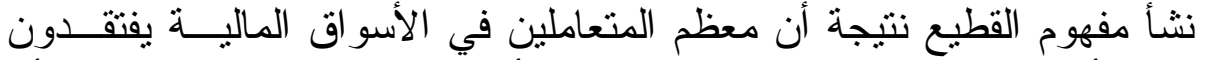
مفهوم القطيع

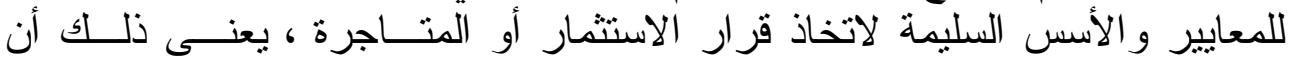

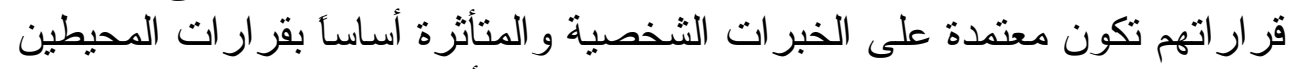

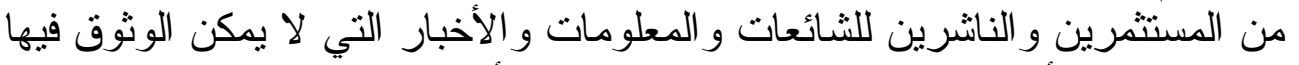

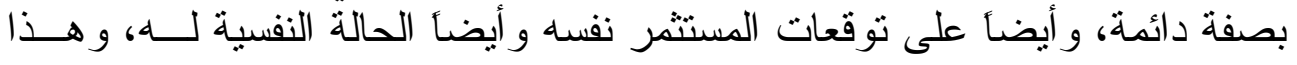

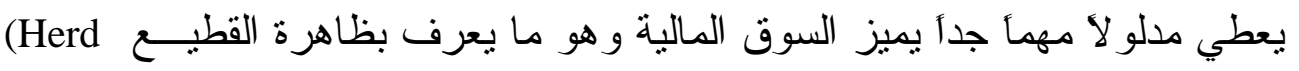
.(Hirshleifer and Siew, 2003, 33) Phenomenon) ما المقصود بطاح التساؤل الآتي:

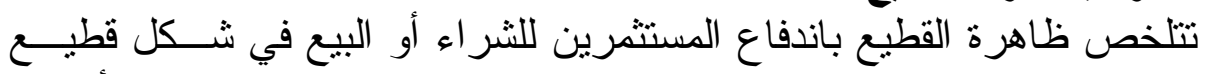

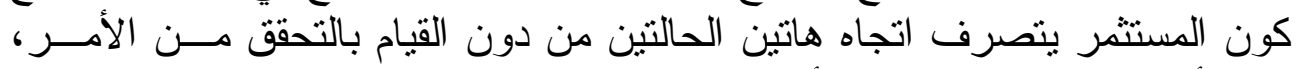

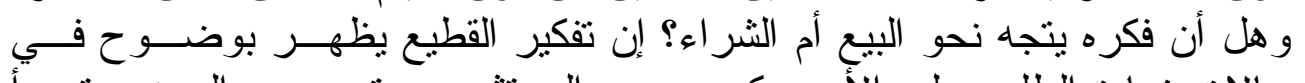

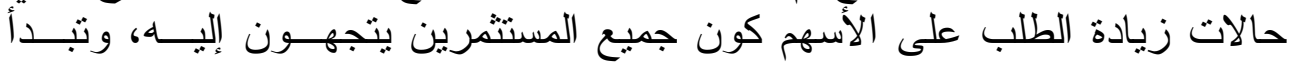




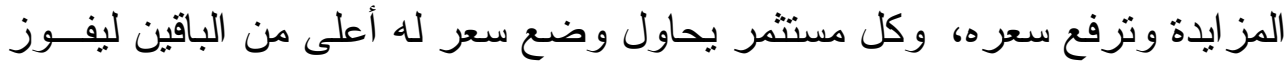

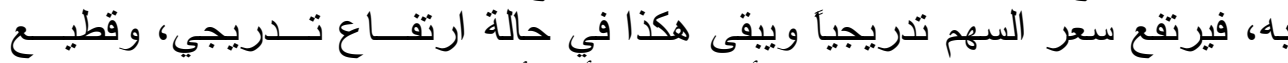

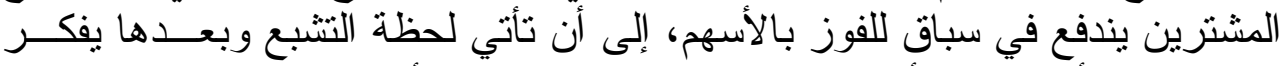

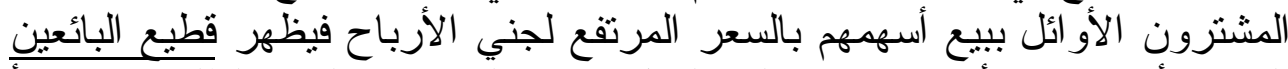

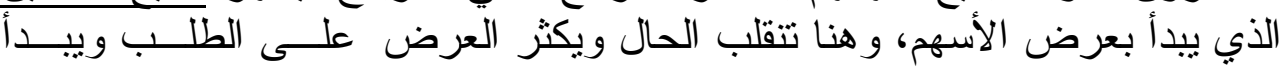

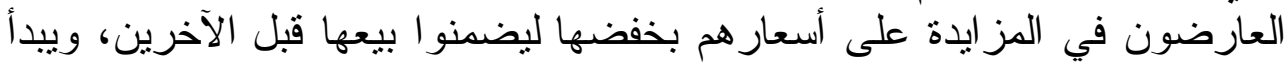

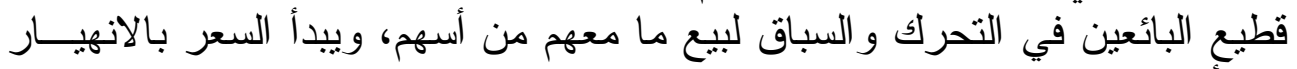

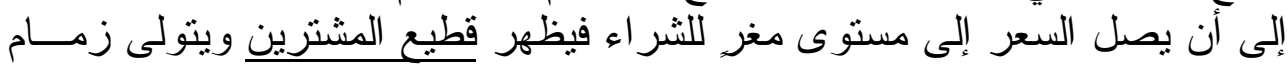

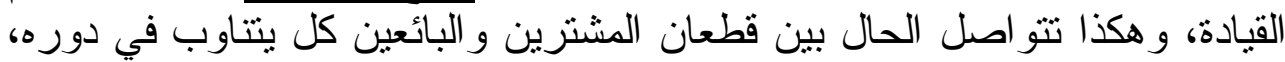

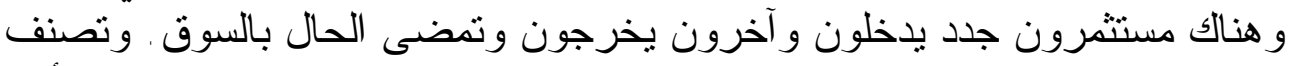

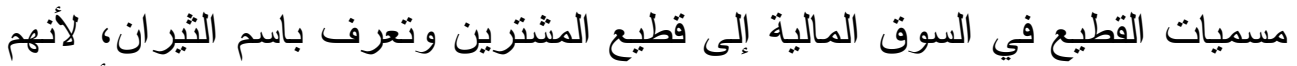

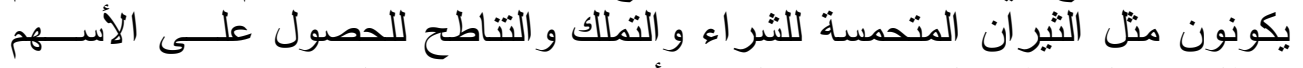

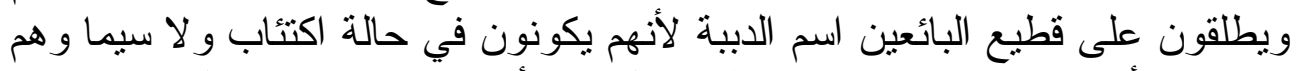

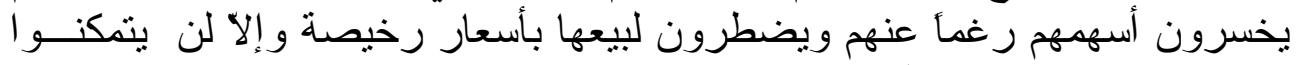
من بيعها على الإطلاق (Scharfstein and Jeremy,1990,469).

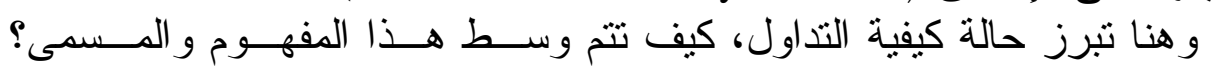

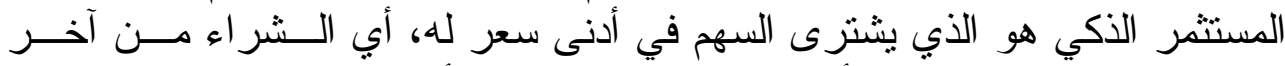

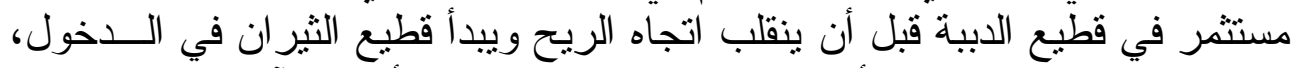

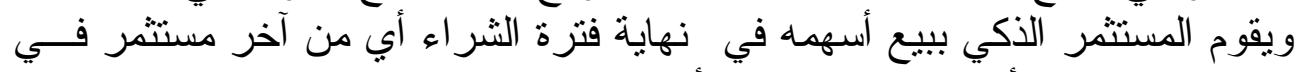

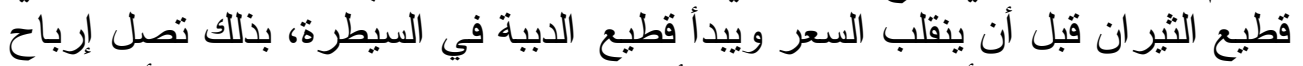

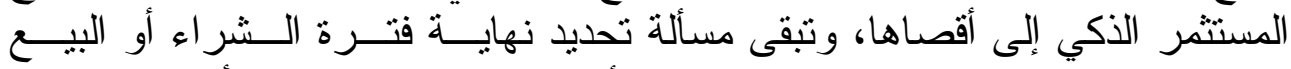

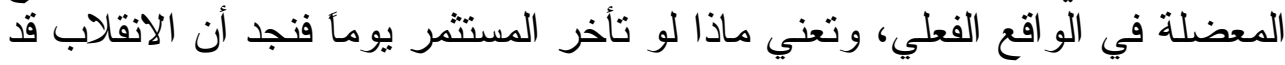
حدث وفاته التدخل الجاد؟ الفيك ولحل هذه المشكلة لابد من التفكير بأن شر اء السهم لن يكون دائماً بأقل سعر

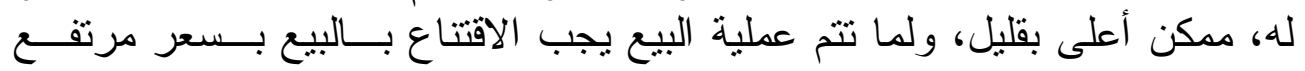

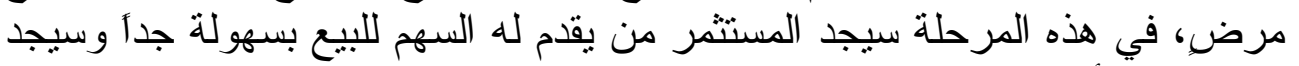

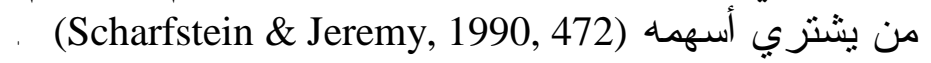

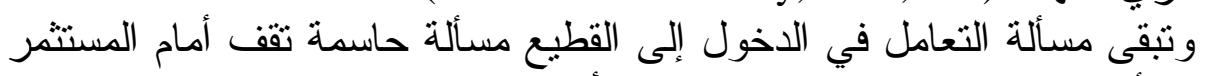

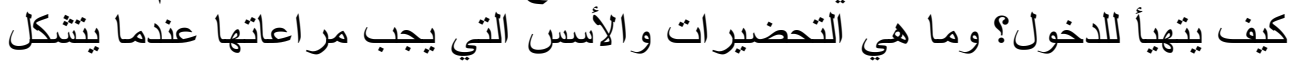

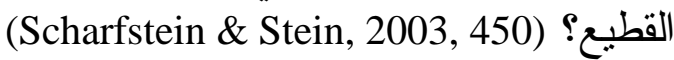

يجب عذه الاسس المستير جمع كل المعلومات و الأخبار من جميع المصادر المتاحة سو اء الداخلية كنها أم الخارجية و العمل على العيل تحليلها.

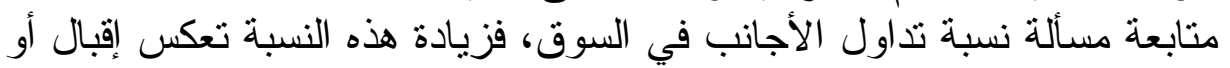
إحجام المستثمر الأجنبي على الدخول في السوق، وبالني فالتالي تعكس مدى جاذبية 


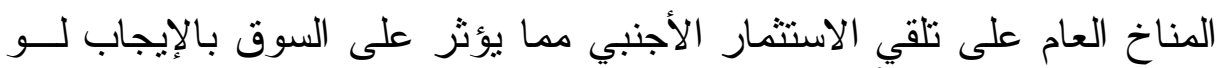

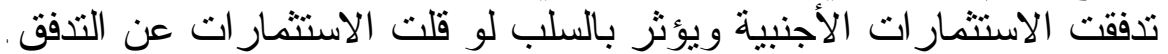

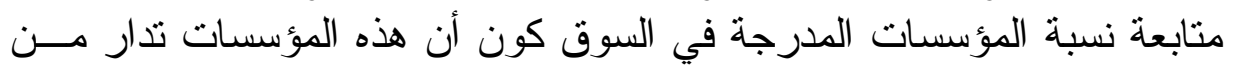

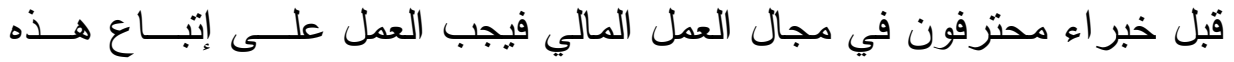

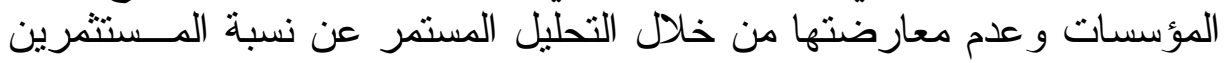

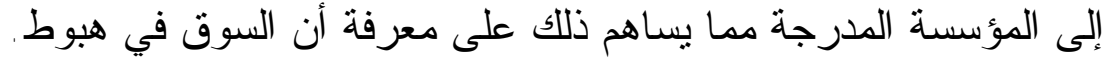

سلوك القطيع Herd Behavior

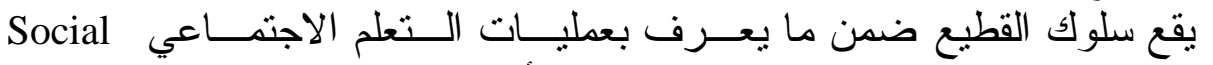
Learning

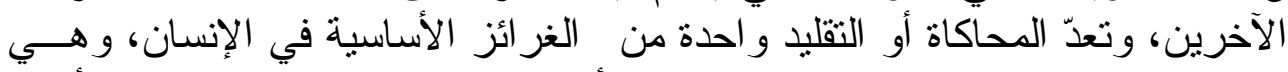

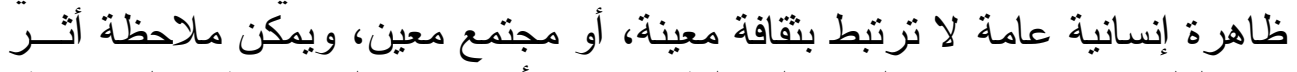

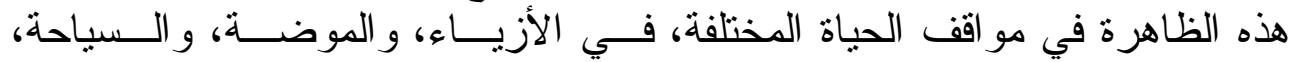

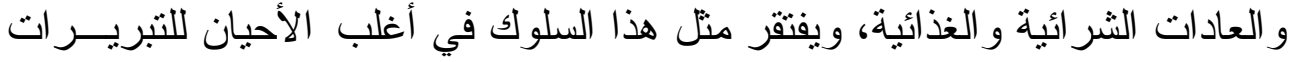
المنطقية .

مما سبق يمكن إعطاء بعض التعاريف لسلوك القطيع ضمن عمل التهل المؤسـسـة

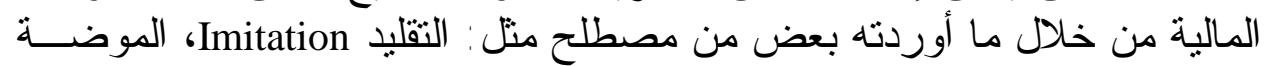

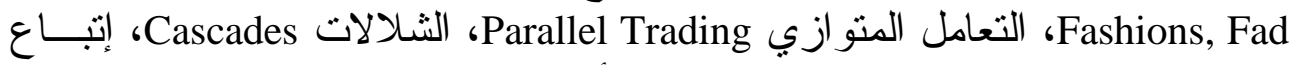

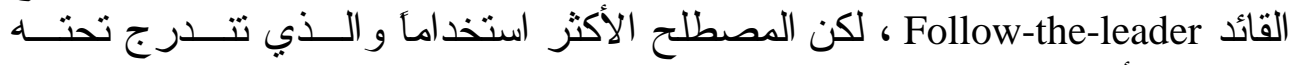
المسميات أعلاه سلوك القطيع Herd Behavior.

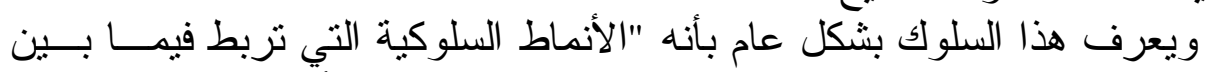

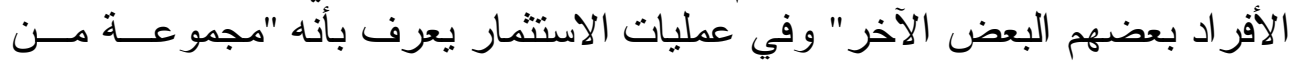

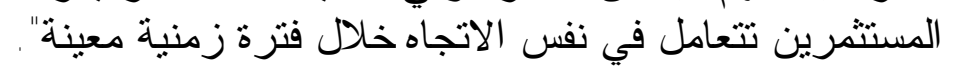

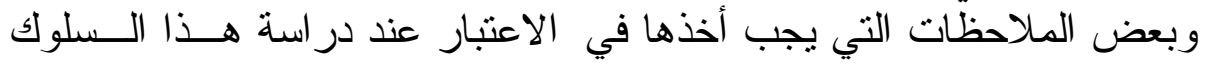

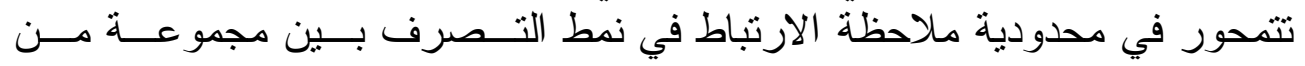

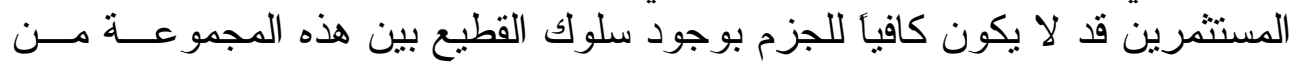

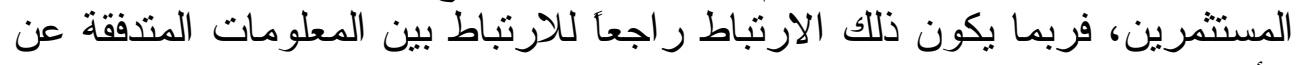

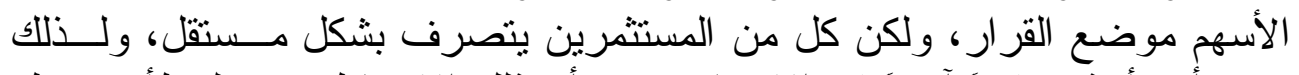

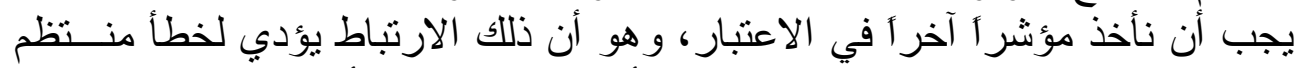

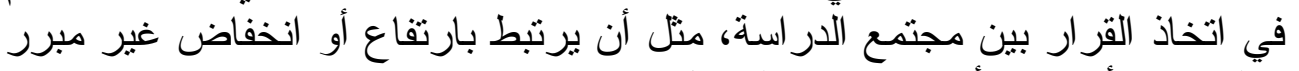

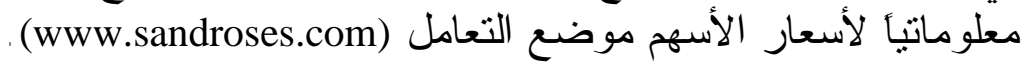

\section{سلوك القطيع في الأسواق المالية}

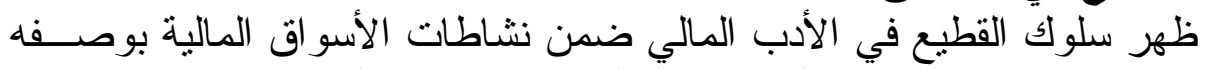

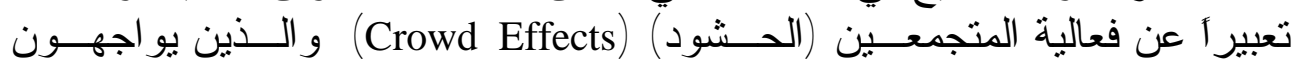
باستمر ار تقلبات أسعار التذاول في السوق، الأمر الذي دعا المهتمين إلــى إيجــاد 


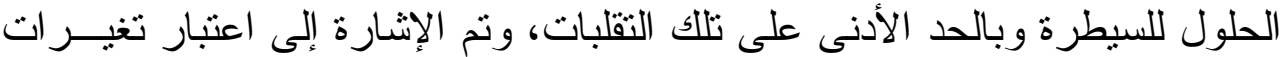

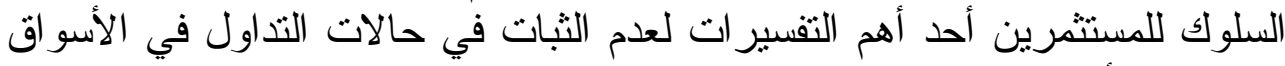

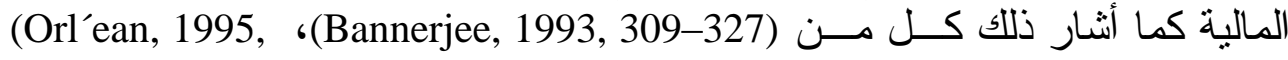
. (Topol, 1991, 786)، (Shiller, 1989, 22-35)، 257-274)

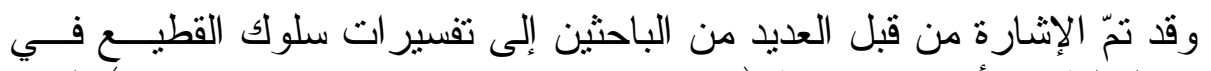

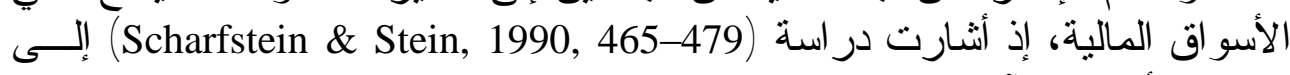

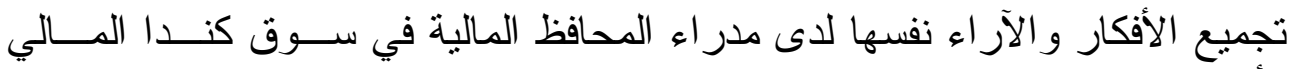

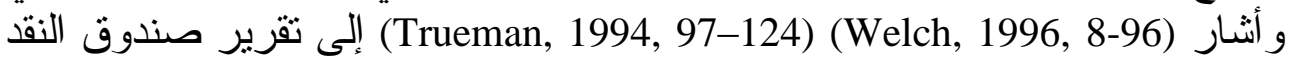

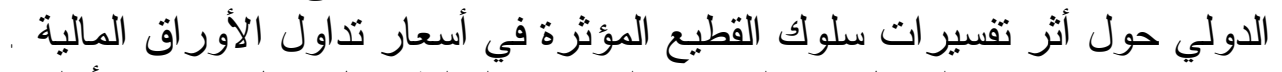

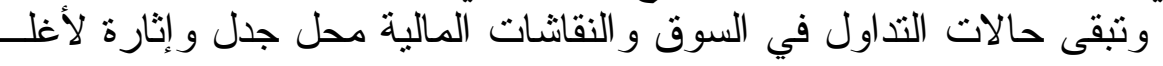

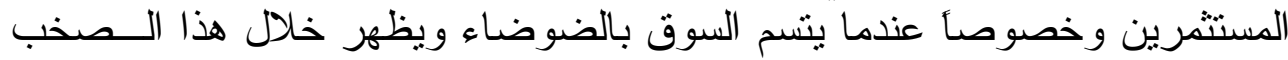

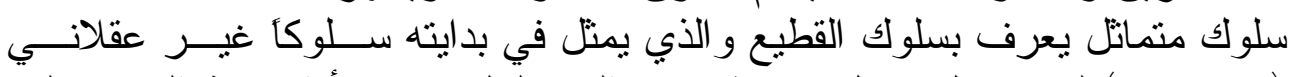

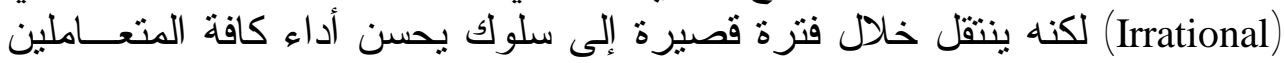

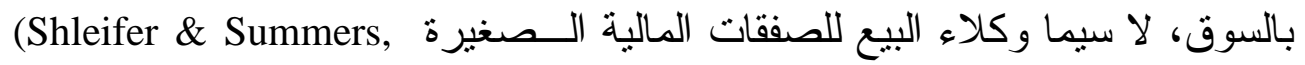

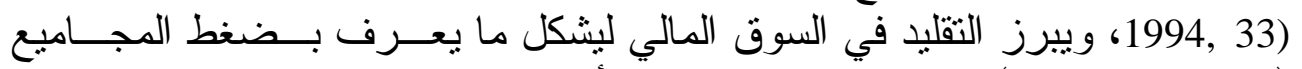

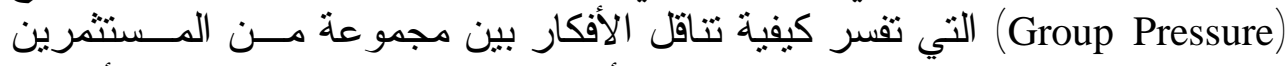

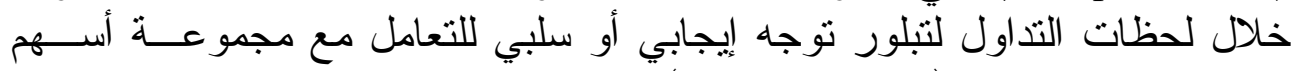
نشطة في تلك اللحظة (Lux, 1998, 143).

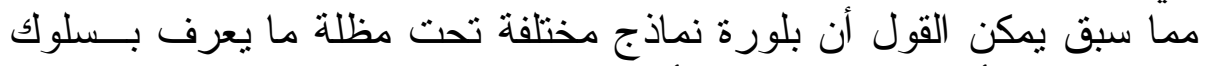

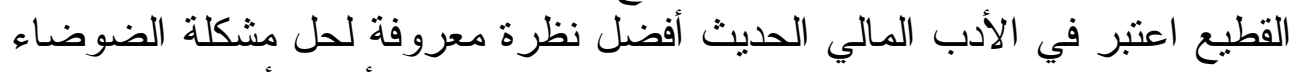

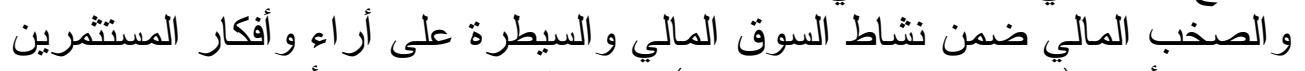

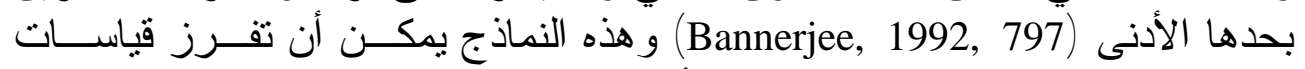

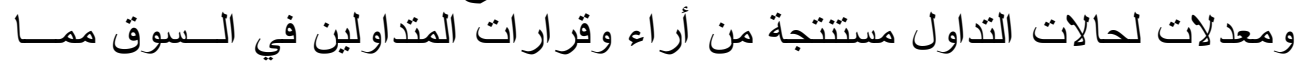

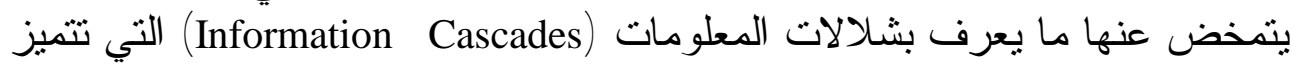

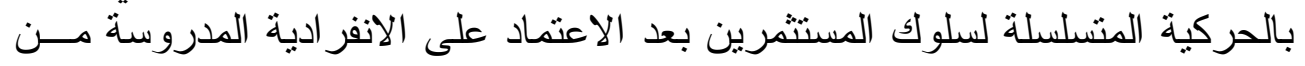

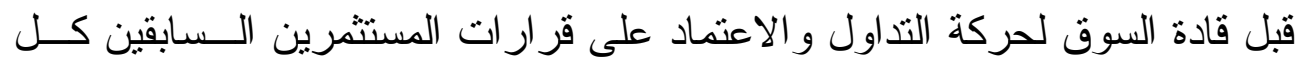
على حدة (Bikhchandani et. al., 1992, 992).

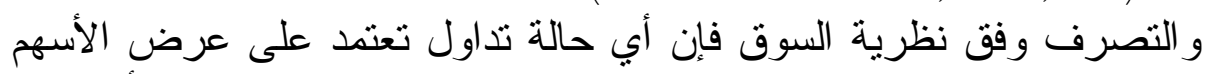

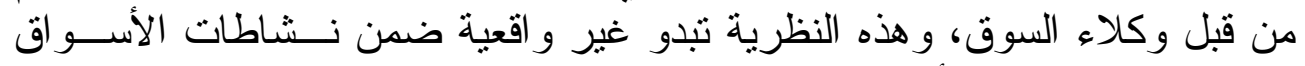

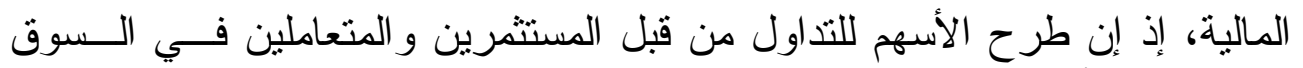

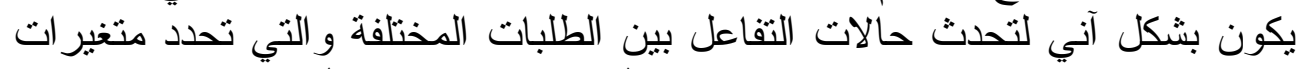
السوق الكلية المتجمعة بشكل غير متتاسق (Orl’ean, 1995, 43).

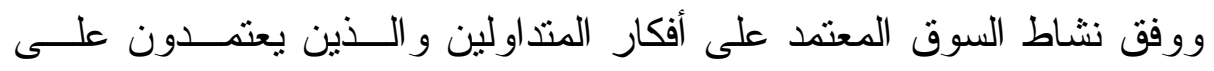

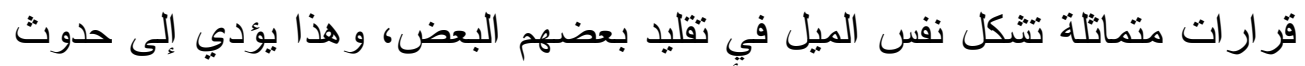

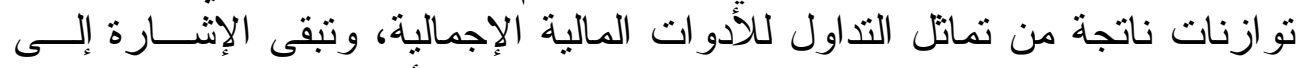

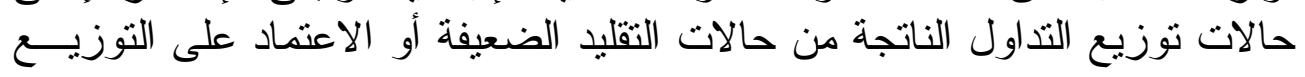




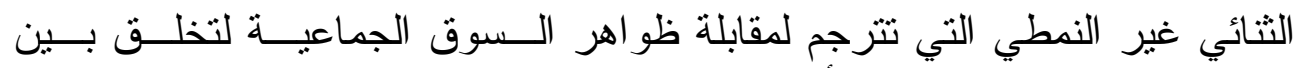

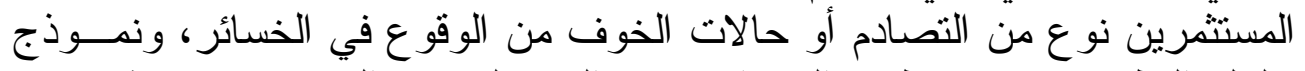

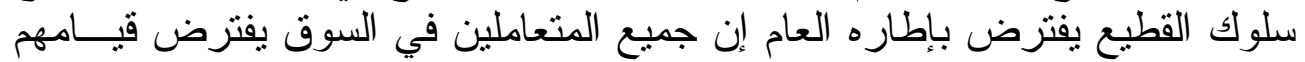

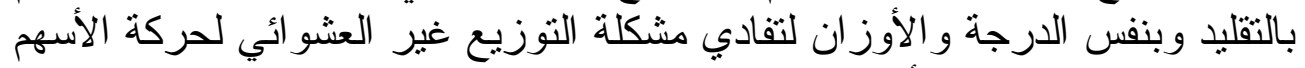

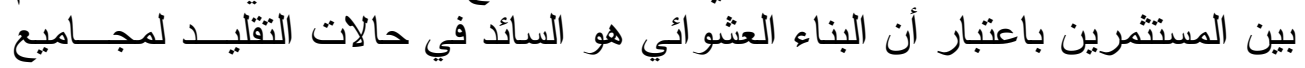

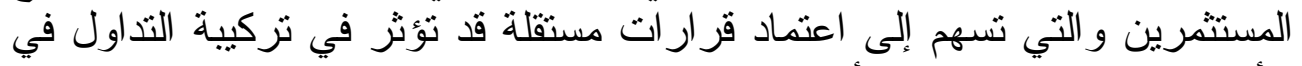

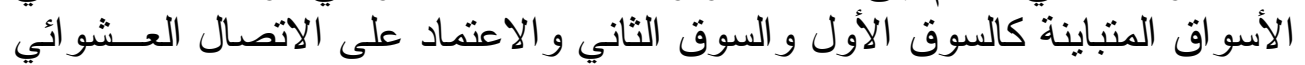
بين مجاميع المستثرين (Orl'ean, 1995, 48). ولتمثيل سلوك القطيع في الأسو اق المالية يمكن الاعتماد على الأسس الآتية :

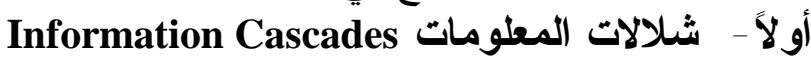

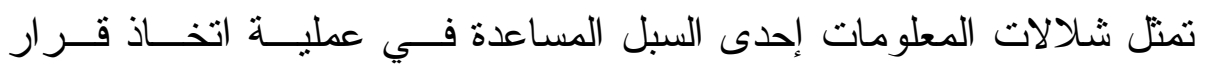

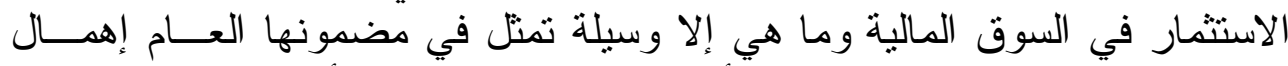

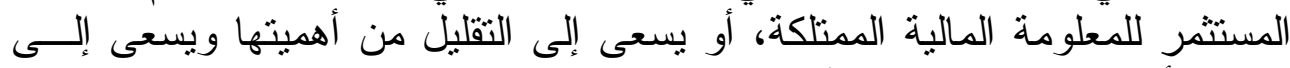

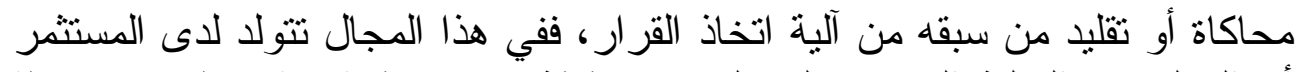

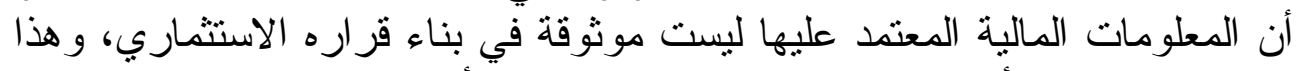

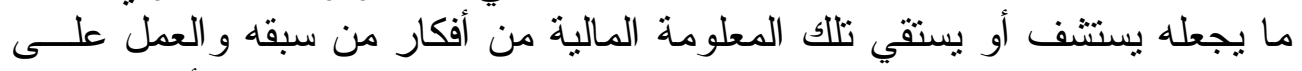

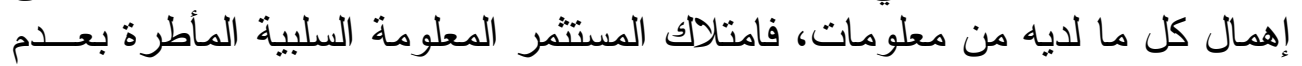

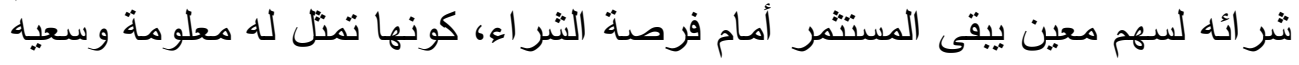

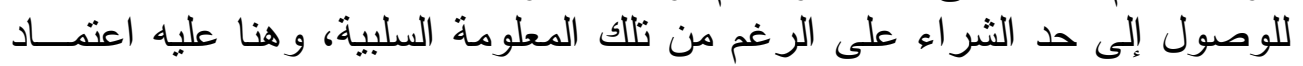

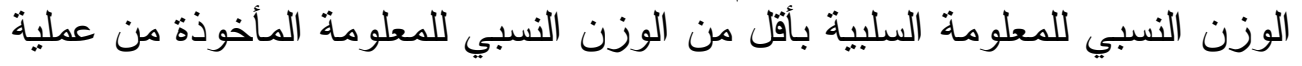

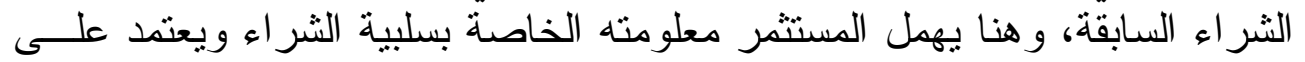

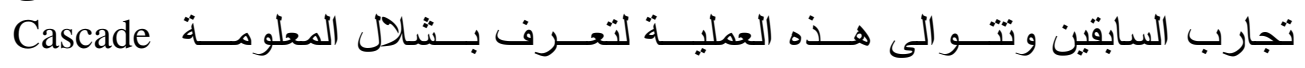
Information

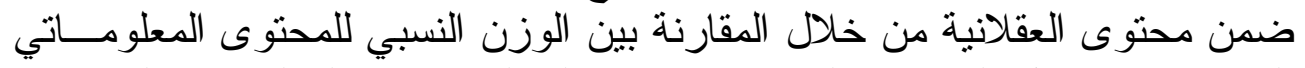

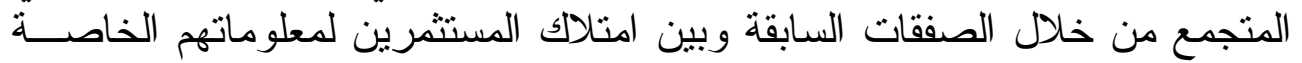

(Chakraborty \& Yilmaz, 2000, 33)

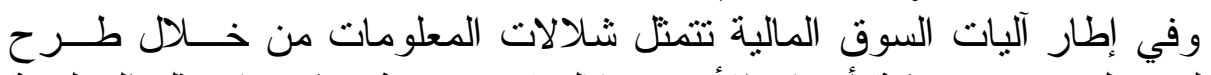

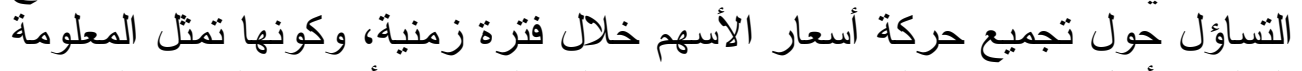

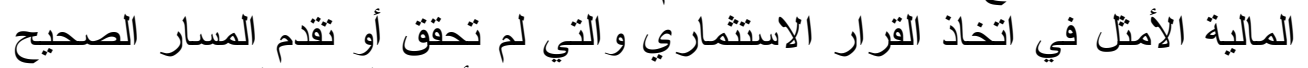

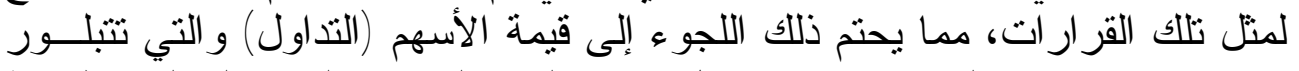

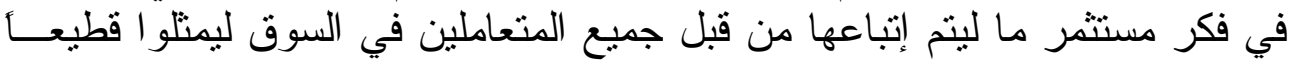
استثمارياً في السلوك المالي. ويمكن تعريف سلوك القطيع على وفق مفهوم شلالات المعلومات على النحو الآتي (Marco Cipriani and Antonio Guarino,2003, 11-17)

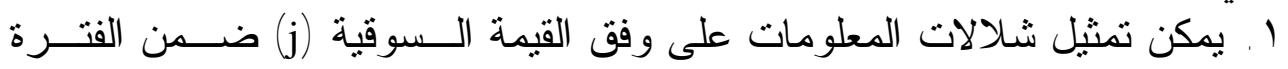

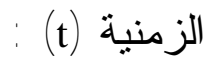


$\operatorname{Pr}\left(h_{t}^{j} \backslash \chi^{j}, H_{t}.\right)=\operatorname{Pr}\left(h_{t}^{j} \backslash H_{t}\right)$ For all $\chi^{j}$ and for all $h_{t}^{j}$

Pr $\left(h_{t}^{j} \backslash \chi^{j}, \mathrm{H}_{t}\right)$

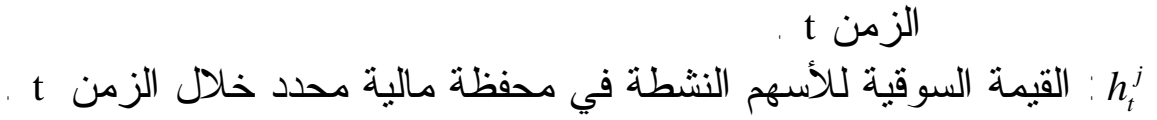
xائد السهم الو احد في المحفظة.

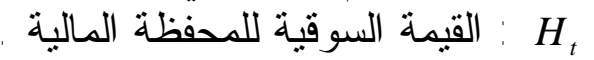

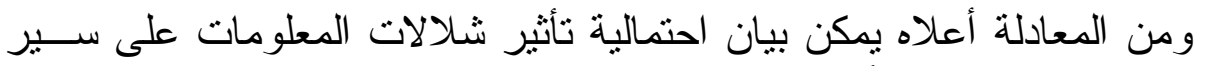

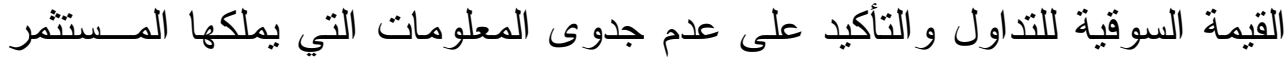

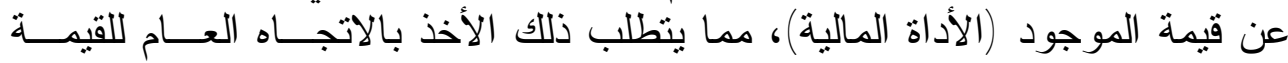

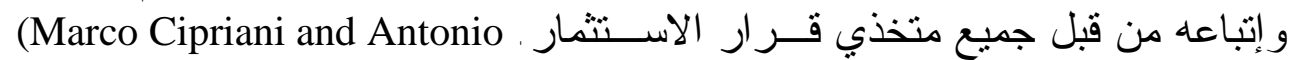

Guarino,2003, 17)

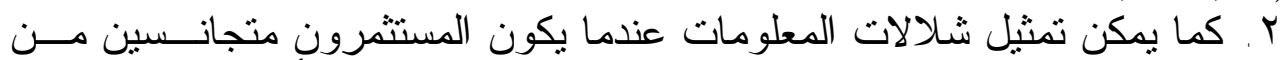

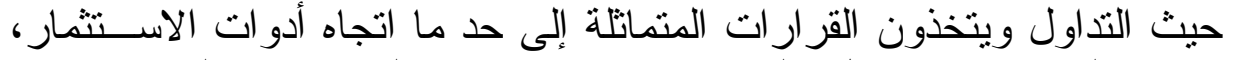

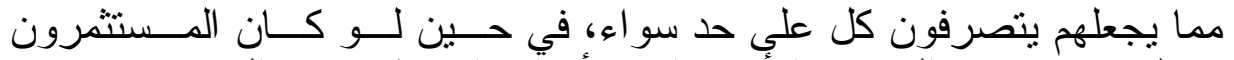

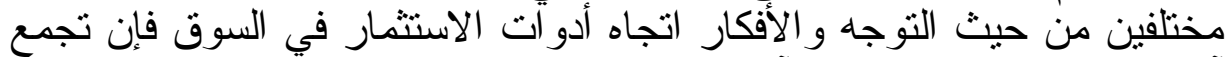

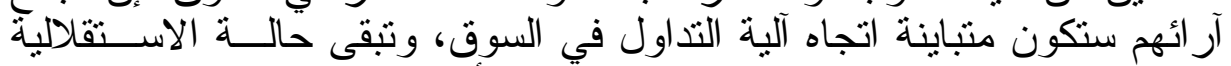

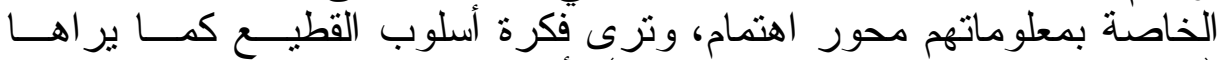
(Smith \& Sorensen, 2000, 371-398)

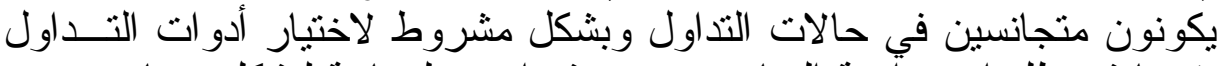

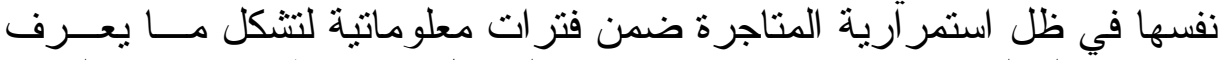

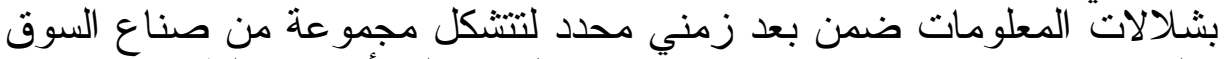

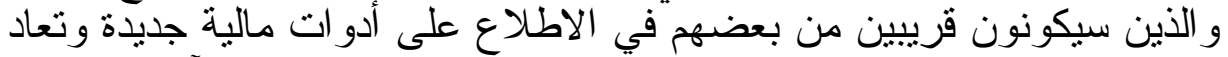

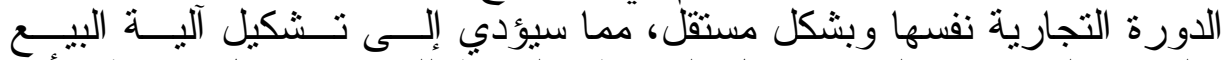

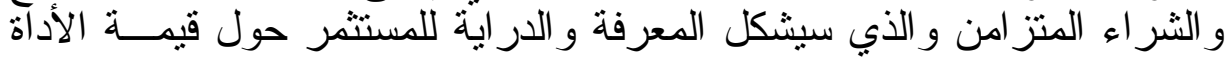

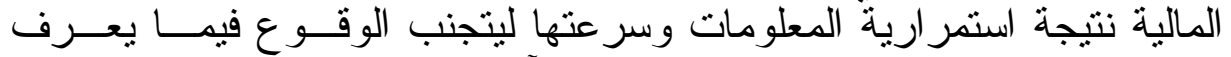

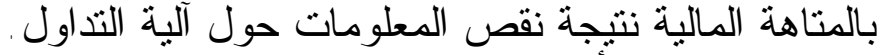

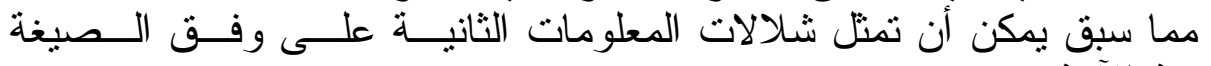

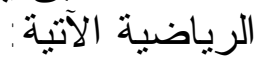

(Smith \& Sorensen, 2000, 371)

$\operatorname{Pr}=E\left(V \backslash H_{T}\right)-g E\left(V^{J} \backslash H_{T}, x^{J}\right)<0$ forall $x^{J}$.

E : : القيمة السوقية للمحفظة المالية. V : القيمة السوقية للسهم ضمن المحفية المفظة المالية.

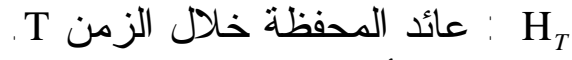
g : عدد الأسهم في المحفظة المالية. 


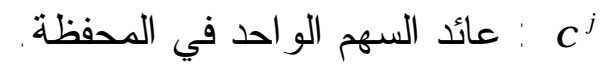

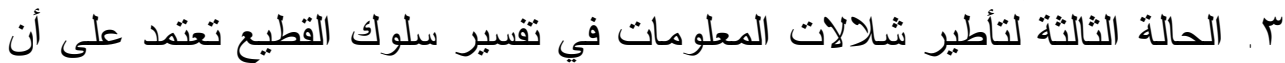

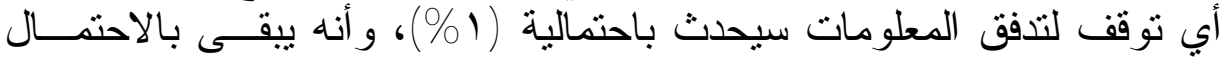

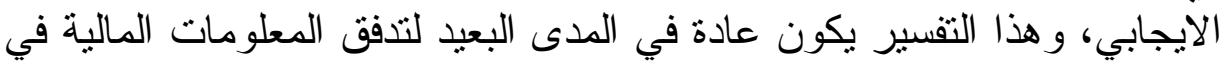

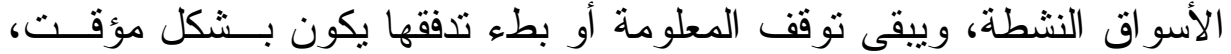

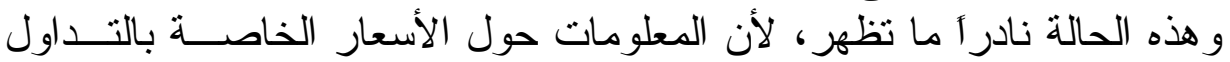

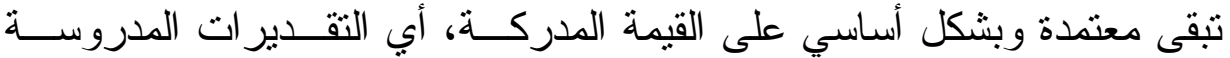

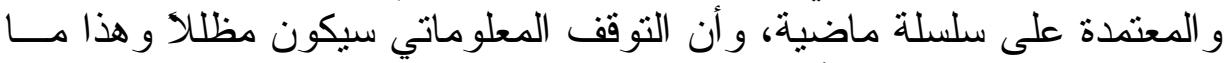

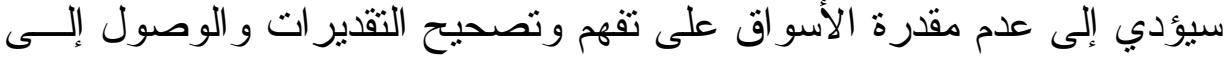

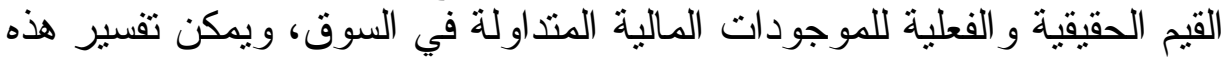
الحالة على وفق الصيغة الرياضية الآتية:

$\operatorname{Pr}\left(\mathrm{E}\left(\mathrm{V}^{\mathrm{J}} \backslash \mathrm{H}_{\mathrm{T}}, \chi^{J}\right)-\mathrm{E}\left(\mathrm{V}^{\mathrm{J}} \backslash H_{T}\right)\langle\varepsilon)=1\right.$

إذ إن: - n

E القيمة السوقية للأسهم الأكثر تداو لا (نثاطأ) ضمن المحفظة المالية.

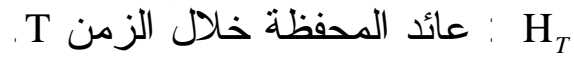

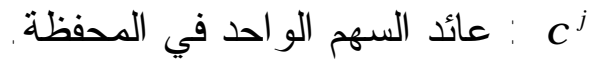

Financial Contagion ثنانياً - العدوى المالية

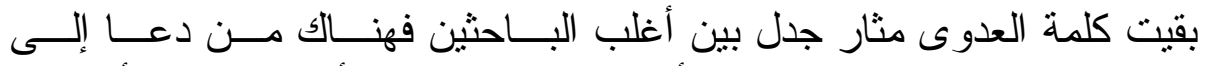

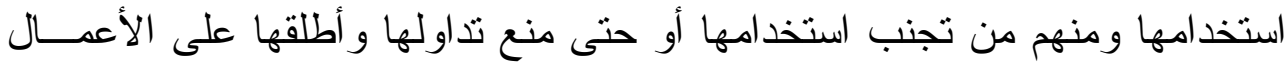

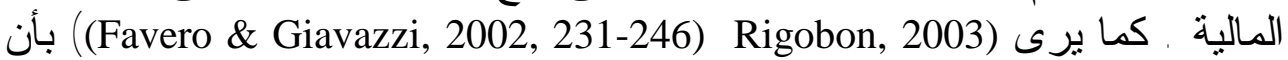
كلمة العدوى أصبحت بمثابة رد فعل بين المستثمرين المتعاملين في الأسواق المالية

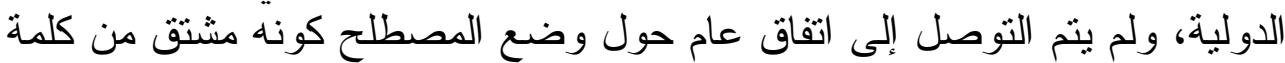

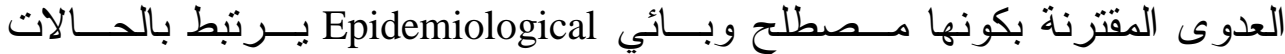
المرضية السلبية، و الذي يمنل عادة حالة الفزع التي تلتئهي بالموت، و انتنشر استخدام

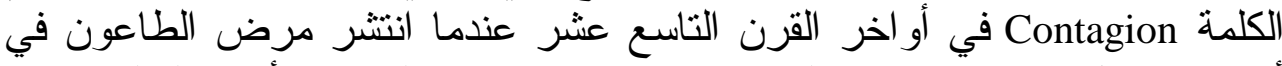

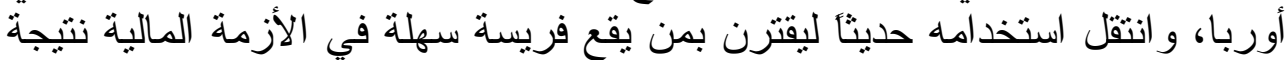

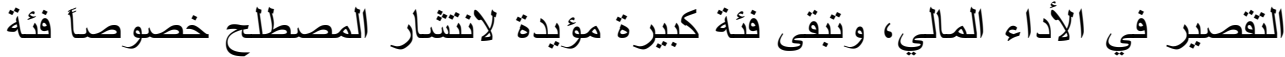

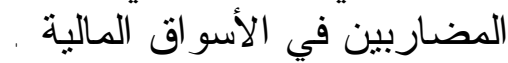

ووفقاً لما سبق يمكن تعريف الاست العدوى على الأساس الكلي بأنها زيادة العائدات

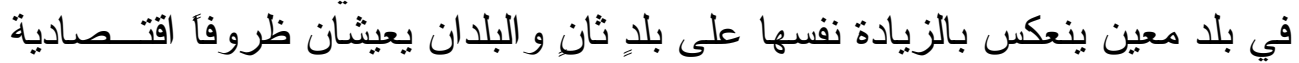

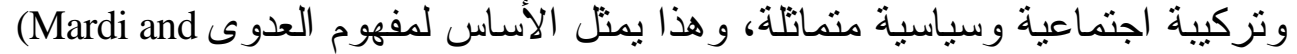
(Demosthenes, 2000, 19)

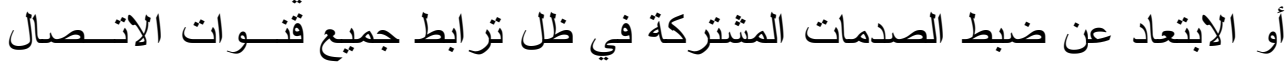


الدكتور المعاضيدي والدكتور العباس [IIV]

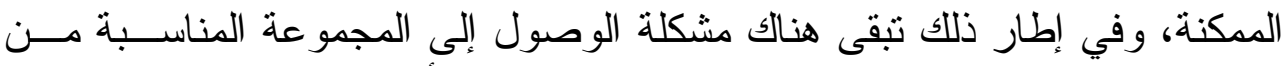

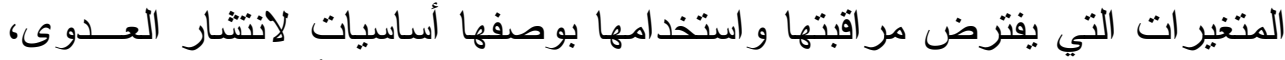

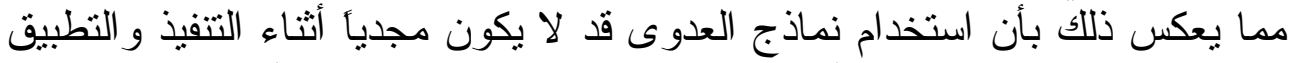

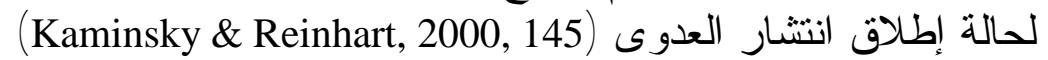

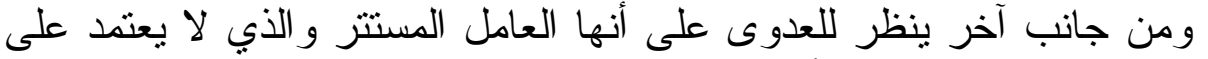

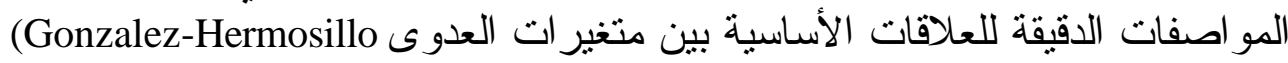
( Martin, 2003, 15) السيطرة على أسس السوق الأساسية و الترابط بين جريان البيانات وتفحص العدئ العدوى . (Mardi \& Demosthenes, 2000, 20)

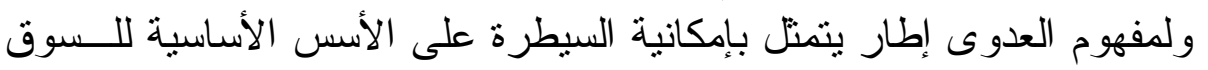

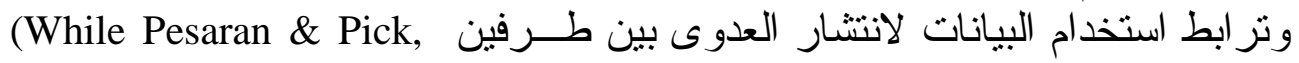

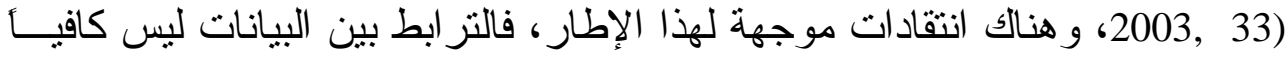

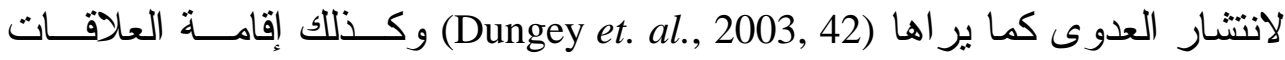

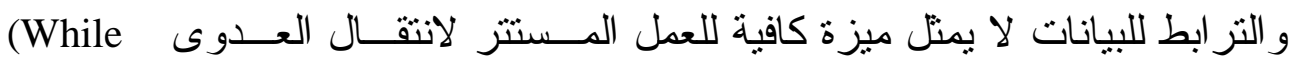

.Pesaran \& Pick, 2003, 21)

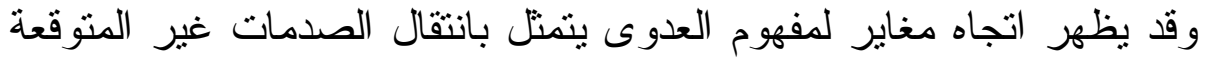

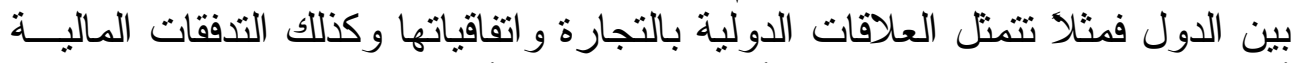

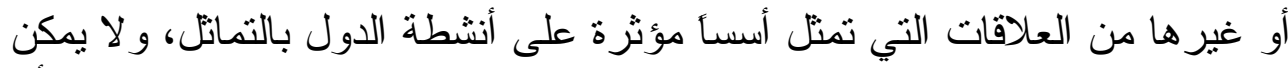

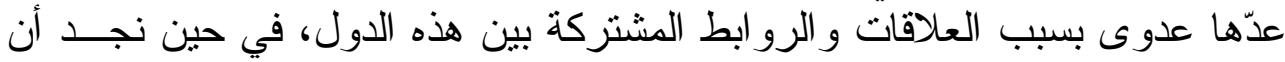

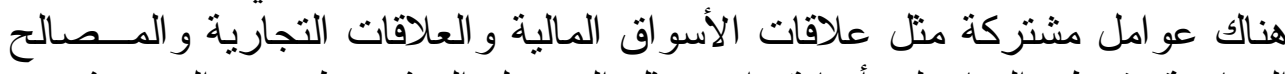

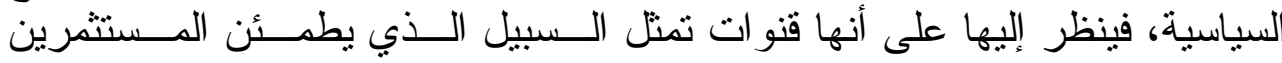

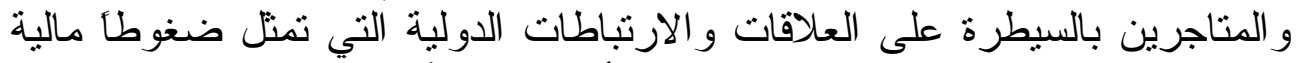

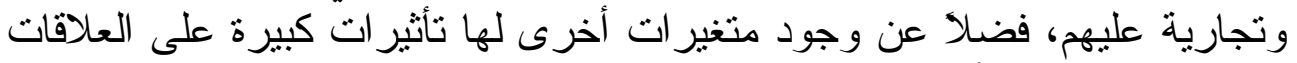

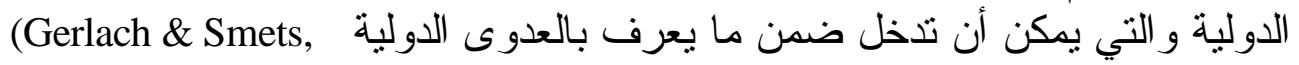
1995, 41)

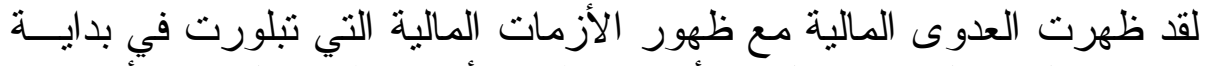

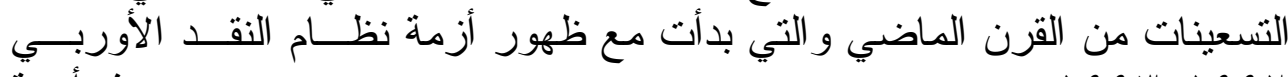

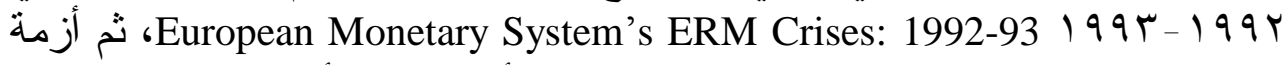

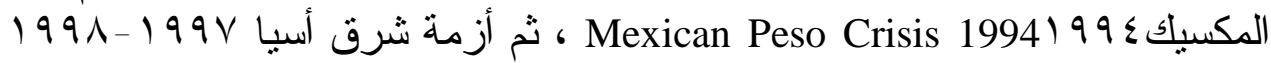

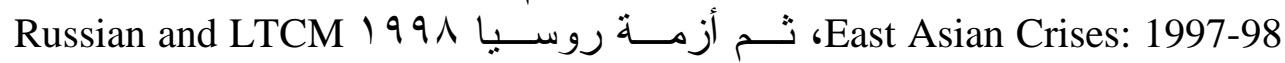

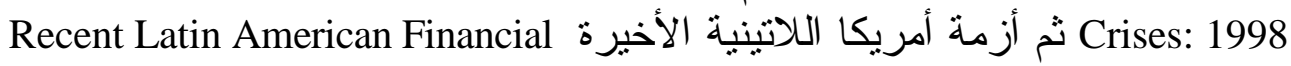

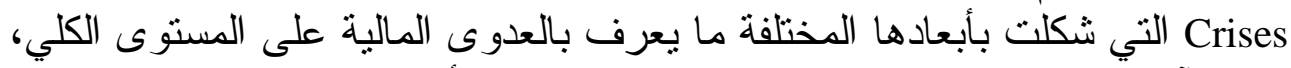

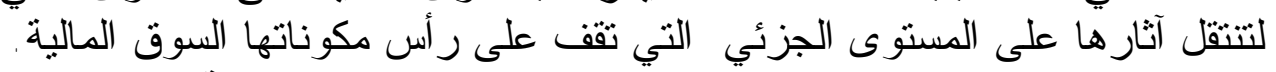

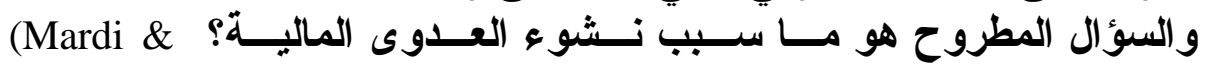

Demosthenes, 2000, 19) 
ا ـ تتشأ العدوى المالية وتتز افق وبشكلٍ متز امن لتمتل سمة من ســمات الأزمــات

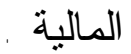

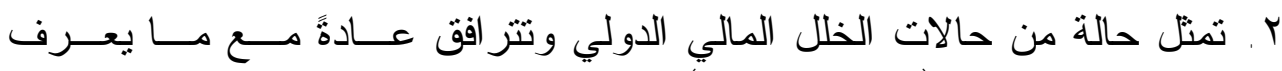

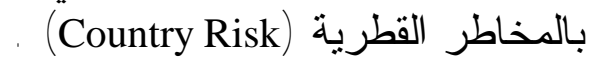

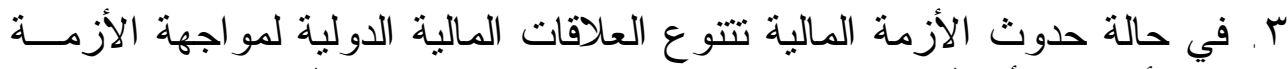

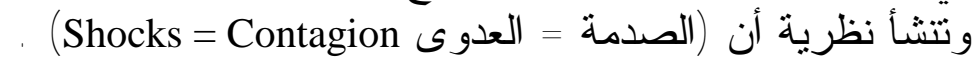

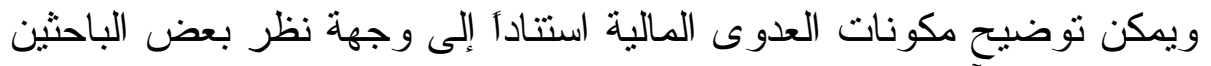

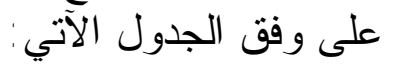

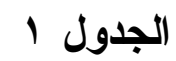

مكونات العدوى المالية وفقاً لوجهة نظر عدد من الكتاب

\begin{tabular}{|c|c|c|c|}
\hline IB 99 & Goldstein 98 & Perry \& Lederman 98 & Lowell et. al. 98 \\
\hline و الفائضمة عن الحاجة الكنة & حركية المنافسة & تأثأثير ات الطنافسة & التزابط الاقتصادي \\
\hline حصول نوبة في شعور & تتشيط التعريف & تأثير ات النشاط & زيادة الوعي \\
\hline 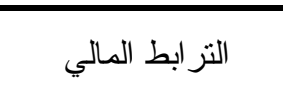 & & الأثنتقات تداولى الأمقان & تالعديل / تثكليلة المحفظة القطيع \\
\hline
\end{tabular}

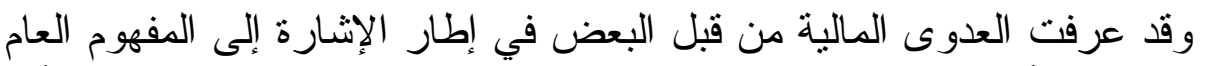

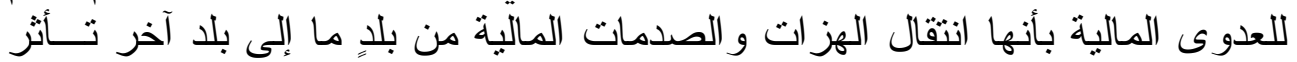
بهذه الهز ات و الصدمات (International Banking, 1999). ويلاحظ أن هذا المفهوم يتسم بالعمومية، إذ لا بل بد من تحديد الروابط الأساسية

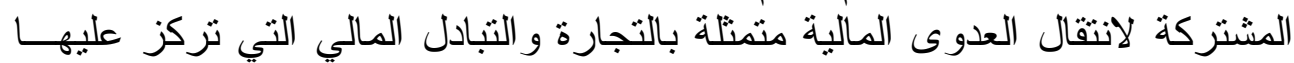

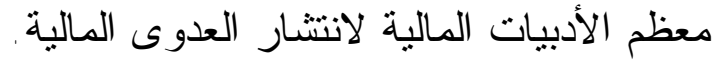

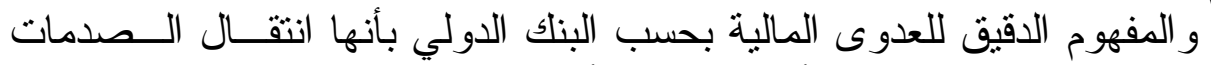

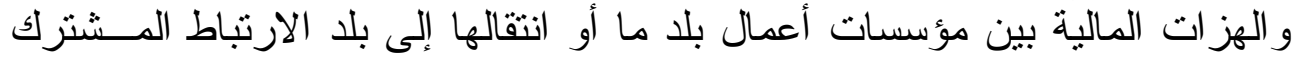

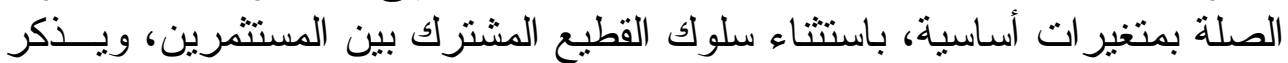

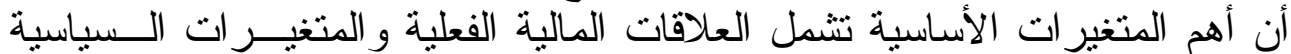

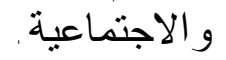

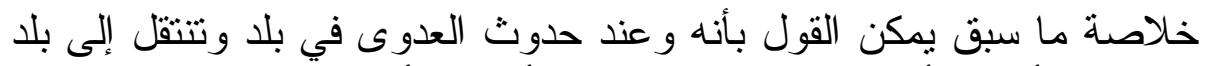

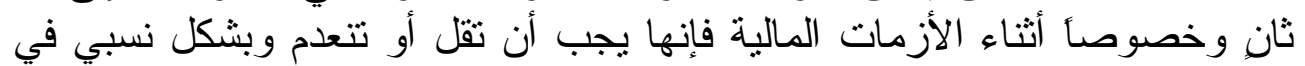

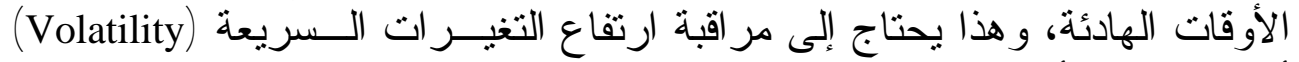

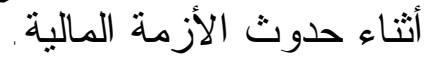

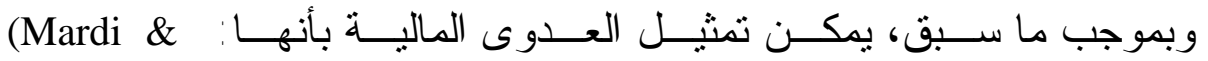

Demosthenes, 2000, 23) 1 . تتنقل بمسبيات أساسية و أهمها الصدمات و الهزات المالية . 
r. يمكن أن لا يكون مبرر لها، ويمكن تجنبها.

ثالثاً - انتشار العدوى في الأسواق المالية

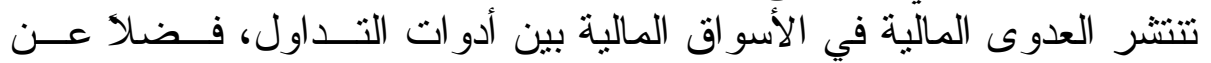

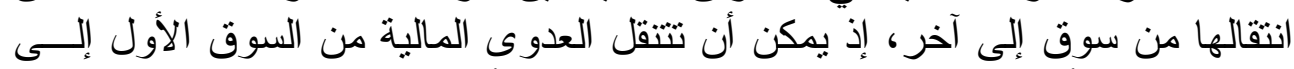

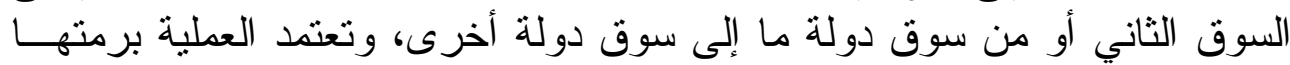

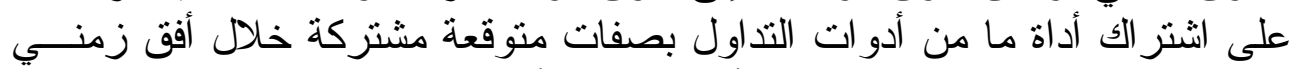

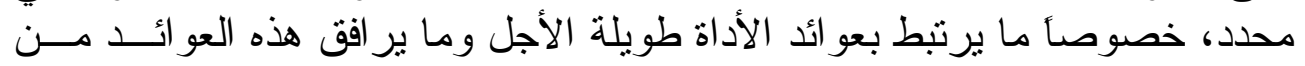

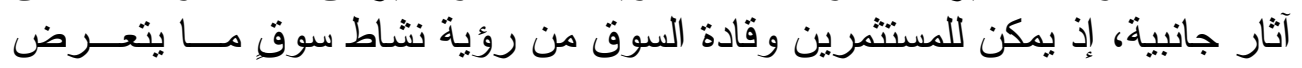

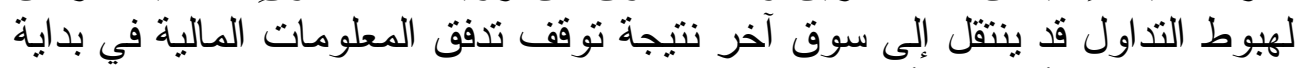

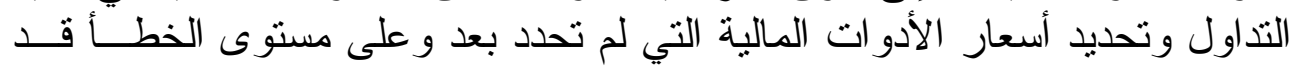

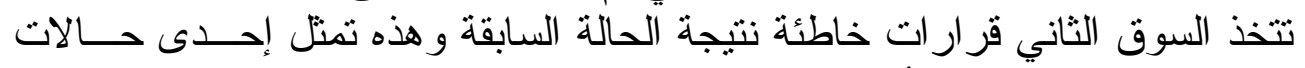

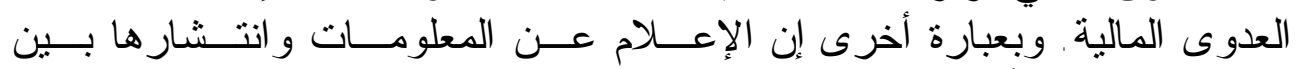

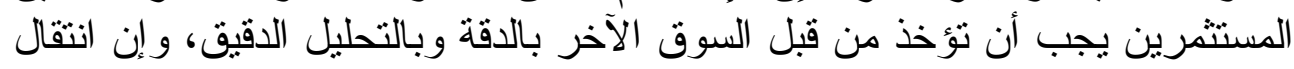

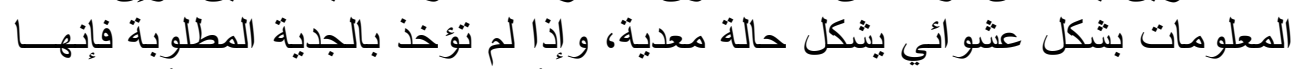

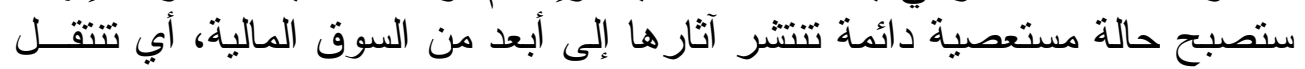

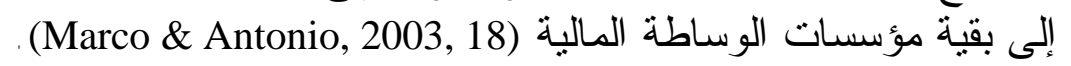

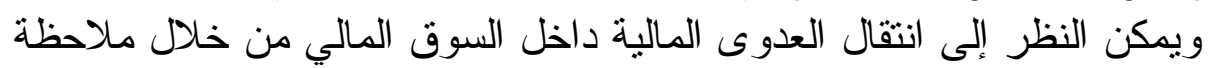

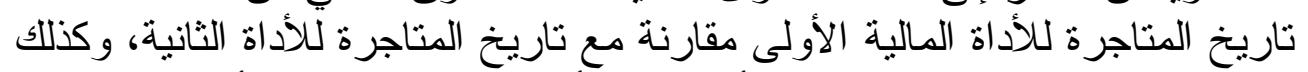

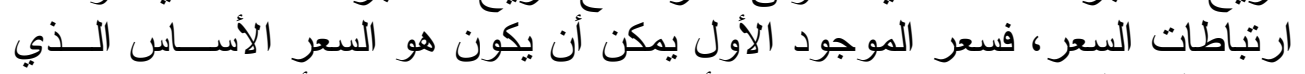

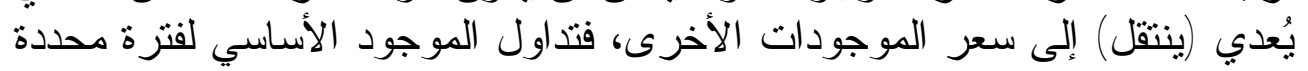

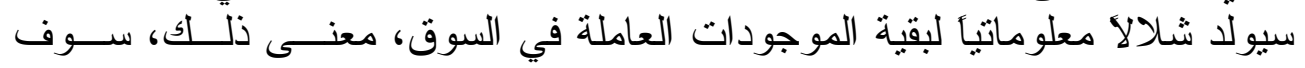

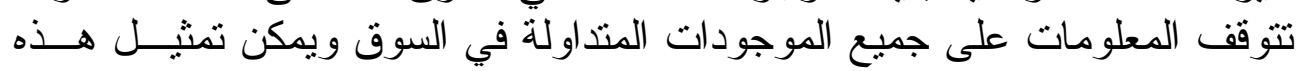

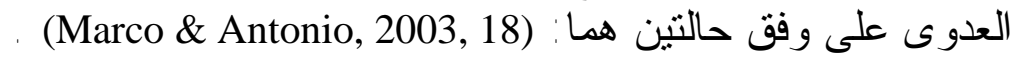

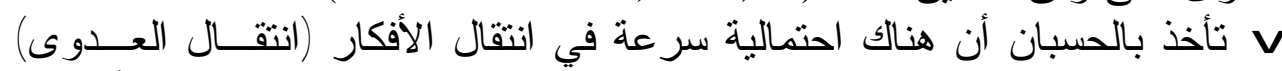

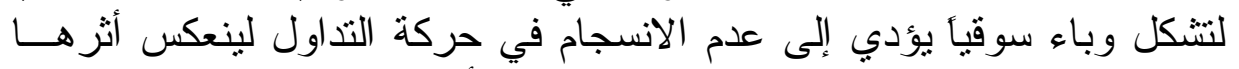

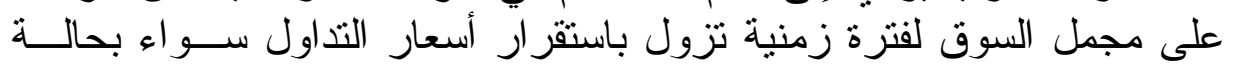

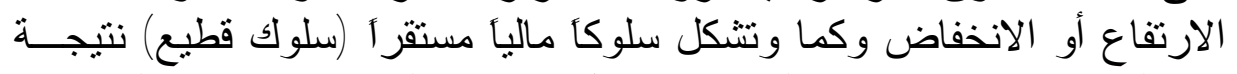

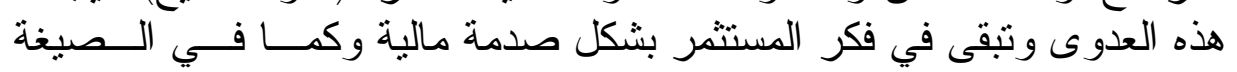
الرياضية الآتية (Marco \& Antonio, 2003, 27)

$\mathrm{E}\left(\mathrm{V}^{\mathrm{A}} \backslash H_{t}\right)-\mathrm{gE}\left(\mathrm{V}^{\mathrm{A}} \backslash H_{t}, \chi^{A}\right)\langle 0 \ldots \ldots \ldots \ldots . . .(\varepsilon)$ $\mathrm{LE}\left(\mathrm{V}^{\mathrm{A}} \backslash H_{t}, \chi^{A}\right)-E\left(V^{A} \backslash H_{t}\right)\left\langle 0\right.$ for all $\chi^{\mathrm{A}}$. 
E : القيمة السوقية للمحفظة المالية. : : القيمة السوقية لسهمين أو أكثر تداولا لا (نثاطا) ضمن المحفظة المالية.

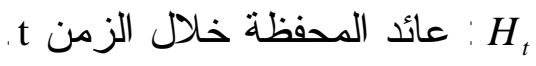
g : ع : عد الأسهم في المحفظة المالية.

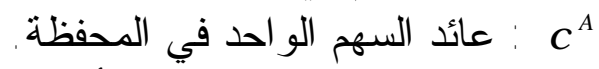

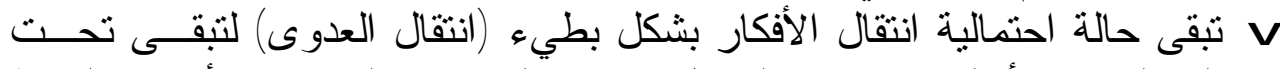

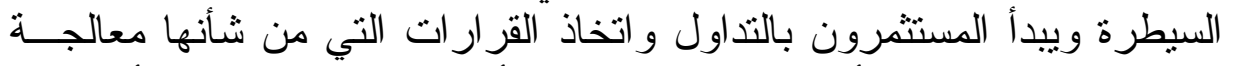

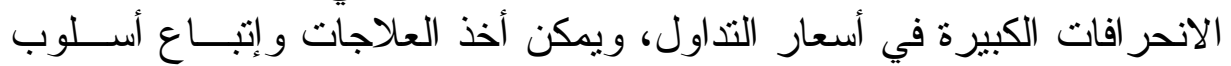

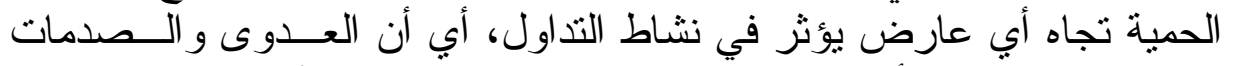

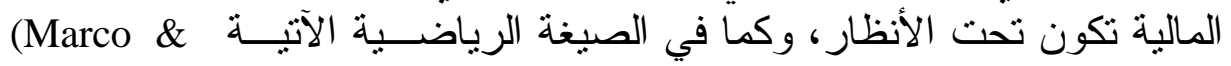
:Antonio, 2003, 27)

$$
\begin{aligned}
& E\left(V^{B} \backslash H_{t}\right)-g E\left(V^{B} \backslash H_{t}, \chi^{B}\right)\langle 0 \quad \ldots \ldots \ldots \ldots . . .(\curlyvee) \\
& L E\left(\mathrm{~V}^{\mathrm{B}} \backslash H_{t}, \chi^{B}\right)-E\left(V^{B} \backslash H_{t}\right)\left\langle 0 \quad \text { for all } \chi^{\mathrm{B}} \ldots \ldots\right.
\end{aligned}
$$

E : القيمة السوقية للمحفظة المالية.

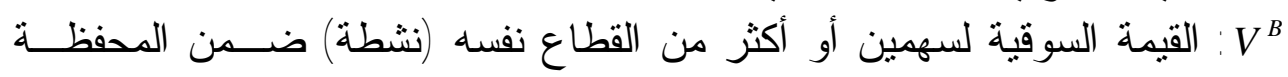
المالية.

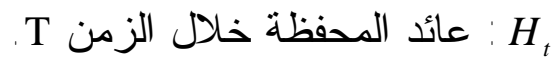
g : ع : عد الأسهم في المحفظة المالية.

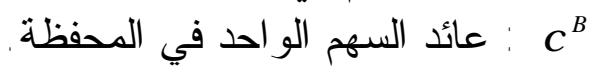

\section{الجانب التطبيقي}

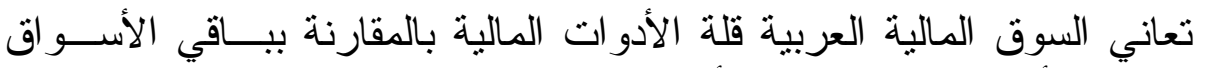

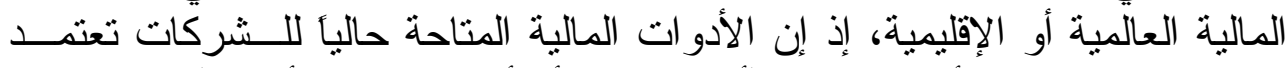

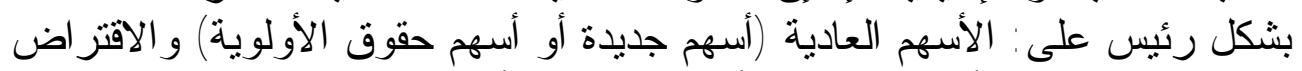

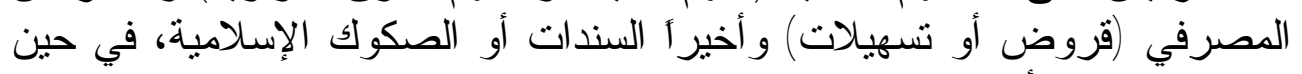

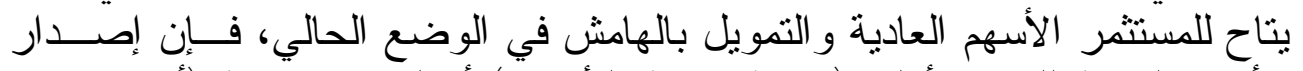

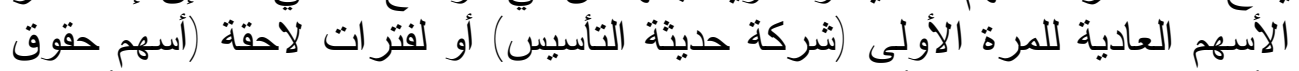

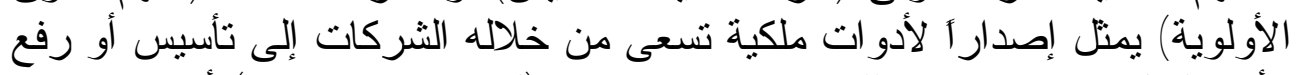

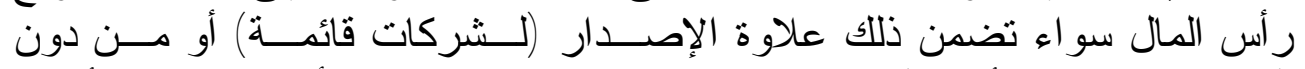

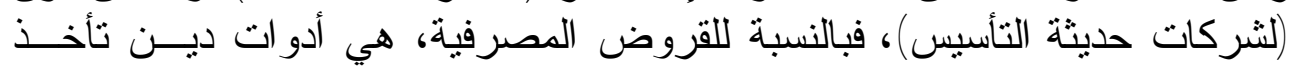

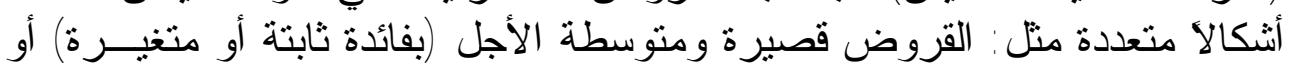




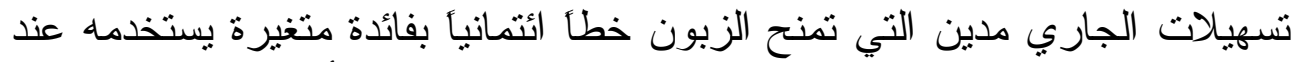

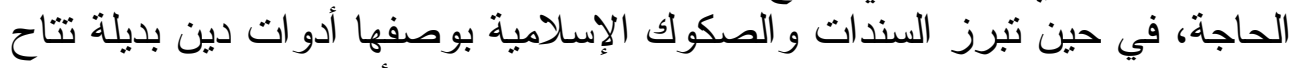

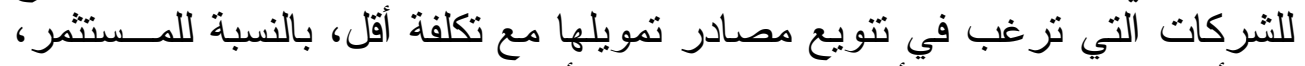

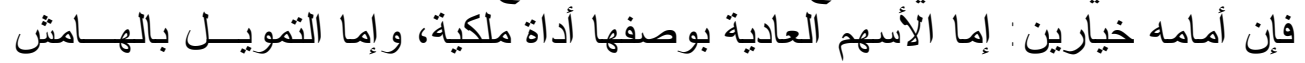

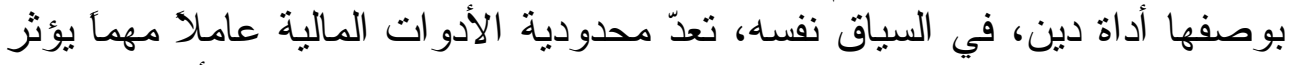

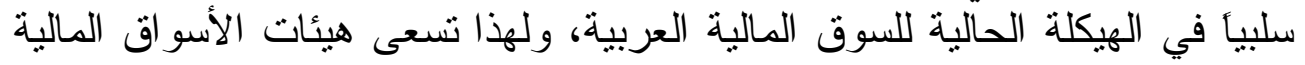

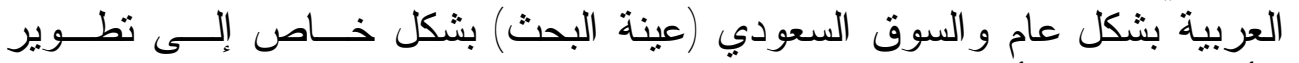

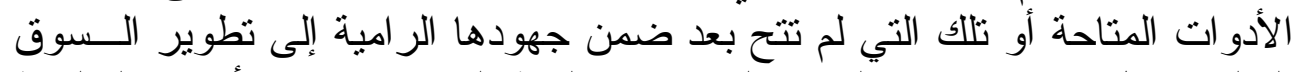

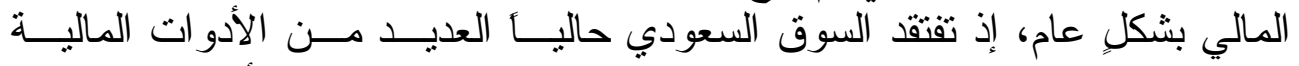

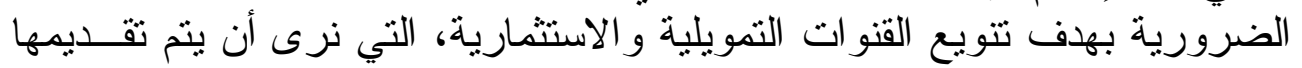

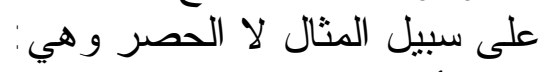

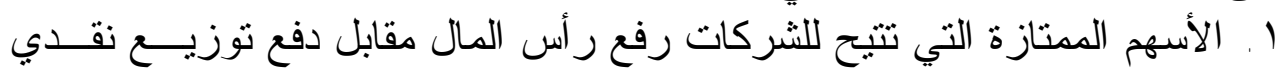

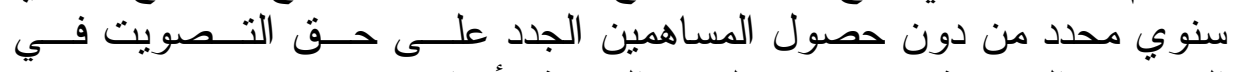

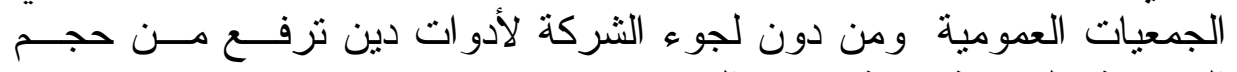

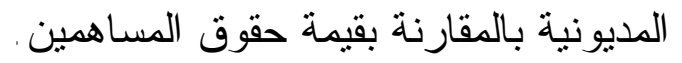

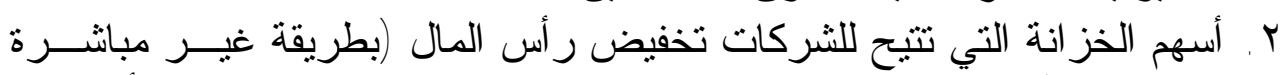

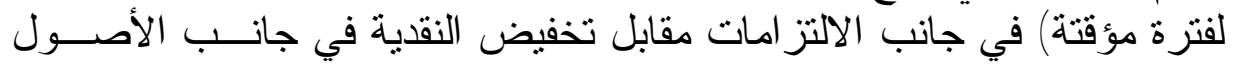

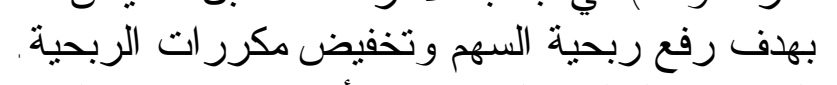

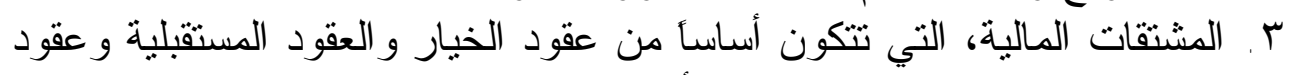

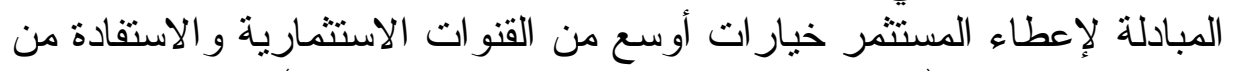

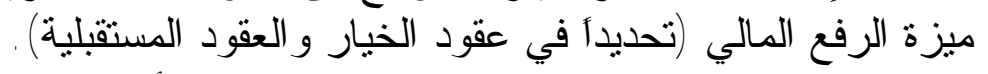

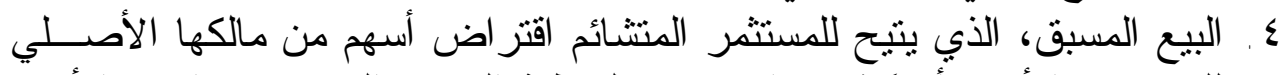

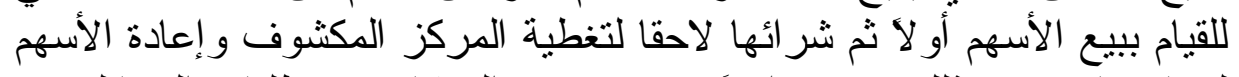

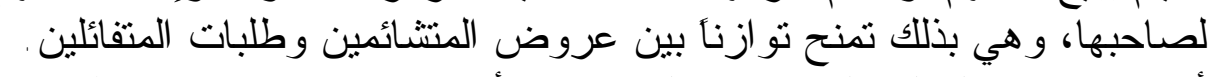

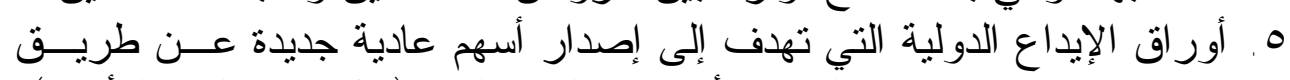

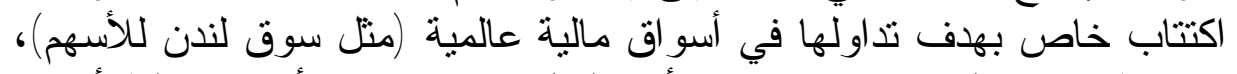

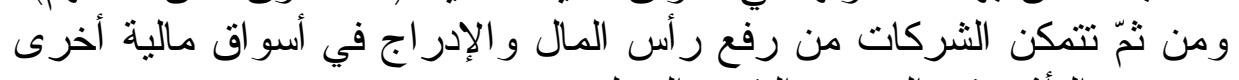

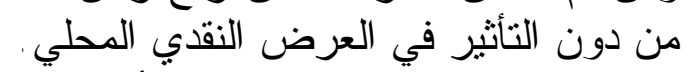

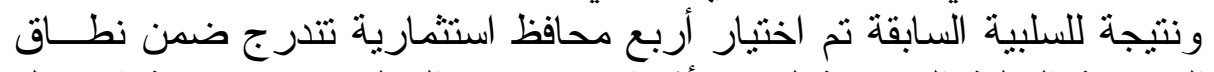

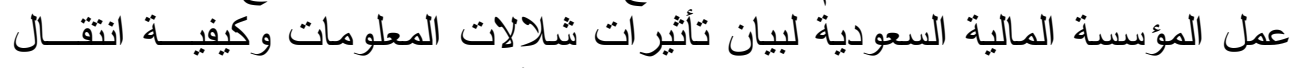
العدوى المالية التي يمكن إيضاحها في الجداول الآتية: 


\begin{tabular}{|c|c|}
\hline \multicolumn{2}{|c|}{ وصف محفظة استثمار صندوق أمريكا الشمالية } \\
\hline صندوق أمريكا الشمالية & الصندوق \\
\hline أمريكا الشمالية & الاسم المختصر \\
\hline 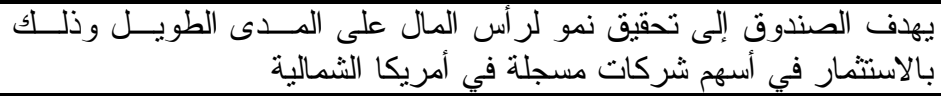 & هدف الصندوق \\
\hline 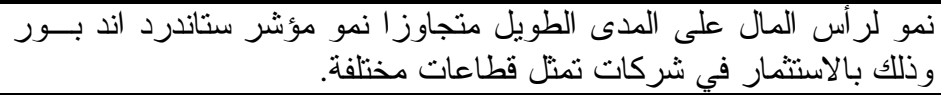 & سياسة الصندوق \\
\hline السعودي الفرنسي & مدير الصندوق \\
\hline السبت، الثنالثاء، الأربعاء & أيام العمل \\
\hline الأسهم الأمريكية & فئة الصندوق \\
\hline تتمية رأس المال & تصنيف الصندوق \\
\hline دولار أمريكي & العملة الأساسية \\
\hline $1996 / 04 / 30$ & تاريخ الابتداء \\
\hline 1.00 & سعر الابتداء \\
\hline- & الفئة الفرعية للصندوق \\
\hline مؤشر ستاندرد اند بور & مقياس الجودة للصندوق \\
\hline $2003 / 05 / 19$ & آخر تحديث \\
\hline
\end{tabular}

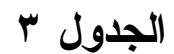

وصف محفظة استثمار صندوق الأسهم الأمريكية

\begin{tabular}{|c|c|}
\hline صندوق الأسهم الأمريكية & اسم الصندوق \\
\hline الأمريكية & الاسم المختصر \\
\hline يهذف الأمريكية الكبروى إلى تتمية رأس المال عن طريق الاستثمار في الثركات & هدف الصندوق \\
\hline الاستثمار في شركات الأمريكية ذات رؤوس الأمو ال الكبيرة & سياسة الصندوق \\
\hline بنك الرياض & مدير الصندوق \\
\hline يوم السبت إلى الخميس & أيام العمل \\
\hline الأسهم الأمريكية & فئة الصندوق \\
\hline تتمية رأس المال & تصنيف الصندوق \\
\hline دو لار أمربكي & العملة الأساسية \\
\hline $1992 / 05 / 26$ & تاريخ الابتذاء \\
\hline 10.00 & سعر الابتذاء \\
\hline- & الفئة الفرعية للصندوق \\
\hline استاندرد اند بور . .0 & مقياس الجودة للصندوق \\
\hline $2003 / 01 / 30$ & آخر تحديث \\
\hline
\end{tabular}




\begin{tabular}{|c|c|}
\hline \multicolumn{2}{|c|}{ وصف محفظة استثمار صندوق الجدول عو الآدفاعي الأمريكي } \\
\hline صندوق النمو الآدفاعي الأمريكي & اسم الصندوق \\
\hline صندوق التحدي & الاسم المختصر \\
\hline التشركات رأس الصناعية علأي المديكية الطويل عن طريق الاستثمار في أسهر & هدف الصندوق \\
\hline الاستثمار في أسهم الثركات الصناعية الأمريكية & سباسة الصندوق \\
\hline 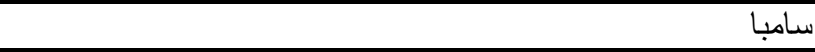 & مدير الصندوق \\
\hline من السبت إلى الأربعاء & أيام العمل \\
\hline الأسهم الأمريكبة & فئة الصندوق \\
\hline تتمية رأس المال & تصنيف الصندوق \\
\hline دولار أمريكي & العملة الأساسية \\
\hline $2003 / 07 / 30$ & تاريخ الابتداء \\
\hline $1,000.00$ & سعر الابتداء \\
\hline- & الفئة الفرعية للصندوق \\
\hline ر راسل .... & مقياس الجودة للصندوق \\
\hline $2003 / 08 / 06$ & آخر تحديث \\
\hline
\end{tabular}

www.tadawul.com.sa

\begin{tabular}{|c|c|}
\hline صندوق مؤشر الأسهم الأمريكية & الصندوق \\
\hline الأسهم الأمريكي & الاسم المختصر \\
\hline 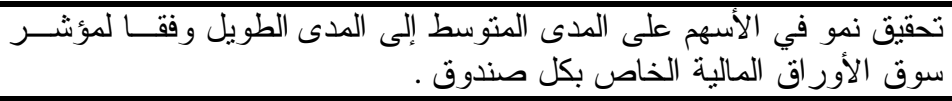 & هدف الصندوق \\
\hline 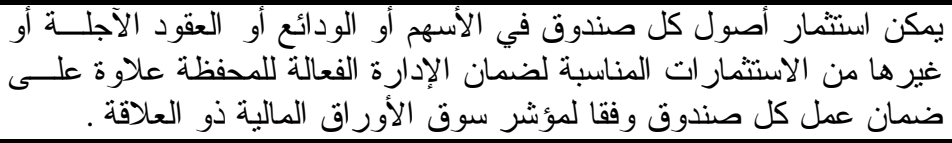 & سياسة الصندوق \\
\hline السعودي البريطاني & مدير الصندوق \\
\hline من السبت إلى الأربعاء & أيام العمل \\
\hline الأسهم الأمريكية & فئَة الصندوق \\
\hline تتمية ر أس المال & تصنيف الصندوق \\
\hline دو لار أمريكي & العملة الأساسية \\
\hline $1997 / 05 / 03$ & تاريخ الابتداء \\
\hline 10.00 & سعر الابتذاء \\
\hline- & الفئة الفرعية للصندوق \\
\hline ستاندر أند بور · . & مقياس الجودة للصندوق \\
\hline $2003 / 11 / 23$ & آخر تحديث \\
\hline
\end{tabular}

www.tadawul.com.sa 
وتم فرز عمليات البيع عن عمليات الثر اء إضافة إلى أيام التوقف في التداول

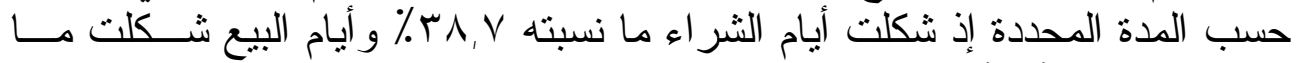

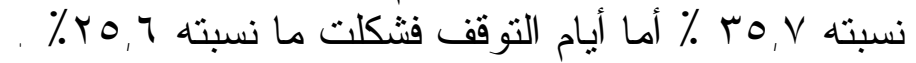

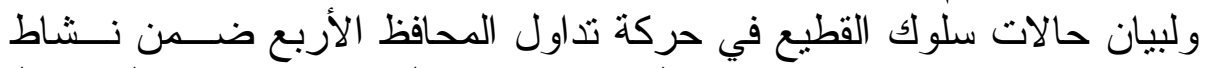

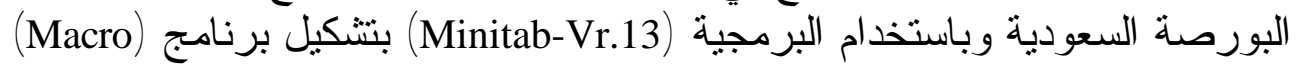

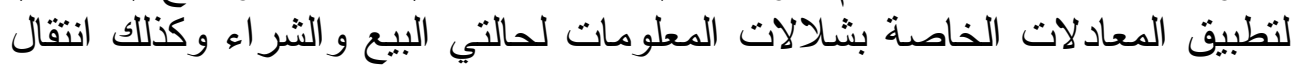

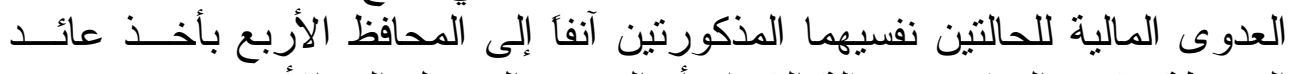
المحفظة وفترة المتاجرة وحالة الثر اء أم البيع تم التوصل البنى التى الأتي:

أولاً - شتلالات المطلومات

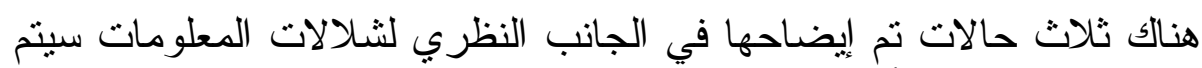

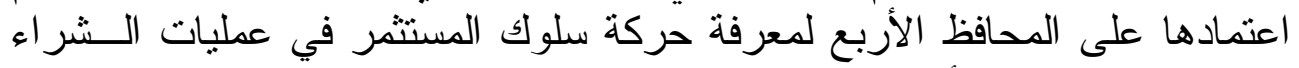

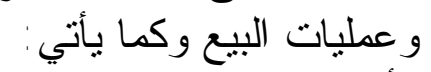

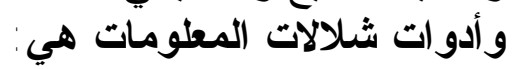

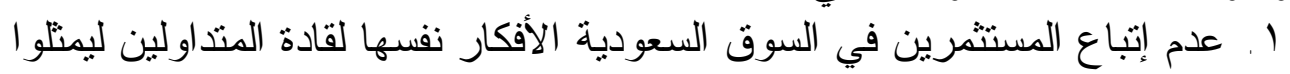
قطيعاً استثماريأ محددأ في السلوك في المالي وهي:

$\operatorname{Pr}\left(h_{t}^{j} \backslash \chi^{j}, H_{t}.\right)=\operatorname{Pr}\left(h_{t}^{j} \backslash H_{t}\right)$ For all $\chi^{j}$ and for all $h_{t}^{j}$

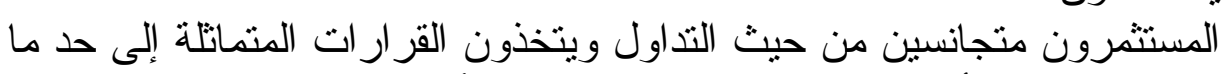

$\operatorname{Pr}=\mathrm{E}\left(\mathrm{V} \backslash \mathrm{H}_{\mathrm{T}}\right)-\mathrm{gE}\left(\mathrm{V}^{\mathrm{J}} \backslash \mathrm{H}_{\mathrm{T}}, \mathrm{x}^{\mathrm{J}}\right)<0$ for all $\mathrm{x}^{\mathrm{J}}$.

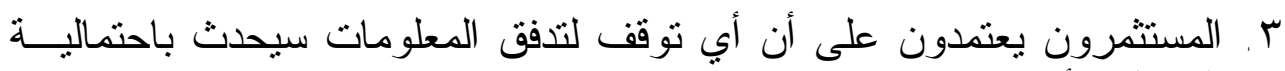

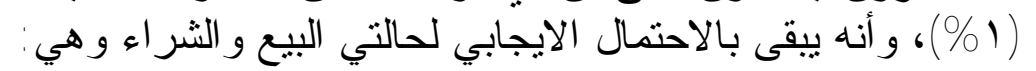

$$
\operatorname{Pr}\left(\mathrm{E}\left(\mathrm{V}^{\mathrm{J}} \backslash \mathrm{H}_{\mathrm{T}}, \chi^{J}\right)-\mathrm{E}\left(\mathrm{V}^{\mathrm{J}} \backslash H_{T}\right)\langle\varepsilon)=1\right.
$$

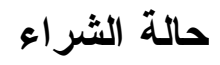

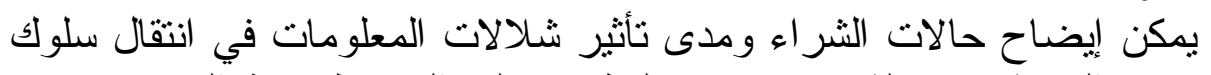

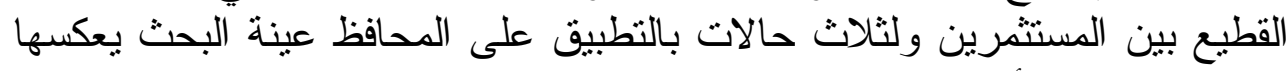

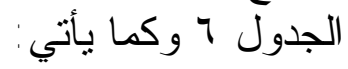




\section{7 الجدول}

احتمالية تأثيرات شلال المعلومات على سلوك المستثمر (سلوك القطيع)

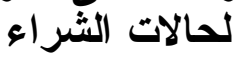

\begin{tabular}{|c|c|c|c|c|c|c|}
\hline St.d & Mean & الأمؤشرّ & الألدفاعي & الأمريكية & أمريكا & للم \\
\hline 0.30 & 0.53 & 0.22 & 0,72 & 0.85 & 0.33 & الأولى \\
\hline 0.009 & 0.54 & 0.53 & 0.55 & 0.54 & 0.55 & الثانية \\
\hline 0.22 & 0.44 & 0.57 & 0.13 & 0.62 & 0.45 & الثالثة \\
\hline
\end{tabular}

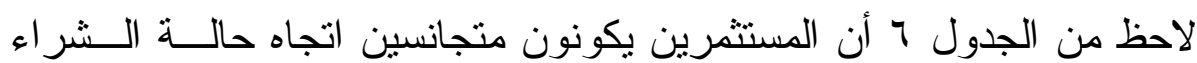

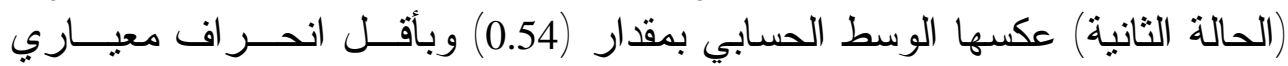

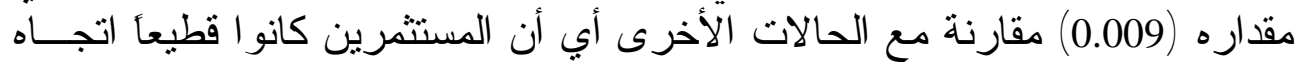
حالة الشر اء ضمن هذه المحافظ و على وفق الحالة الثانية.

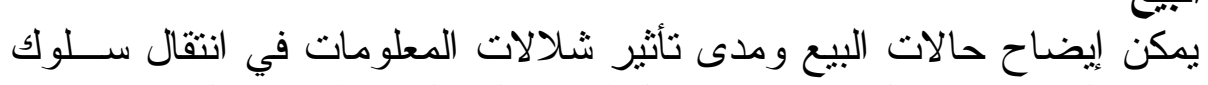

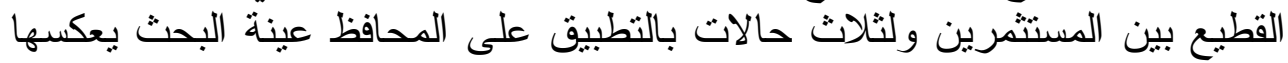
الجدول V وكما يأني :

$$
\text { الجدول }
$$

احتمالية تأثيرات شلال المعلومات على سلوك المستثمر (سلوك القطيع)

\begin{tabular}{|c|c|c|c|c|c|c|}
\hline St.d & Mean & مؤشر الأسهر & النمو الأدفاعي & الأمريكية: & أمريكا & الحالة المحفظة \\
\hline 0.009 & 0.65 & 0.65 & 0.64 & 0.66 & 0.66 & الأولى \\
\hline 0.15 & 0.33 & 0.45 & 0.44 & 0.12 & 0.33 & الثانية \\
\hline 0.25 & 0.42 & 0.16 & 0.32 & 0.77 & 0.43 & الثالثة \\
\hline
\end{tabular}

يلاحظ من الجدول V عدم إتباع المستثمرين في السوق الأفكار نفسها لقــادة

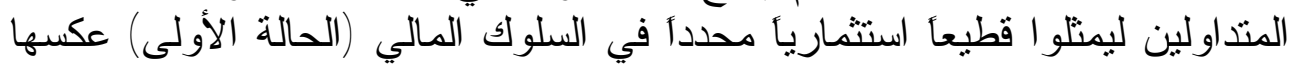

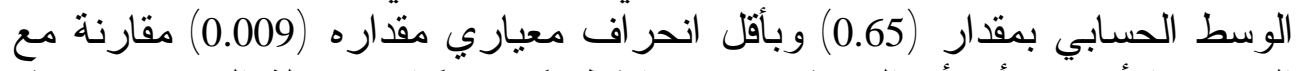

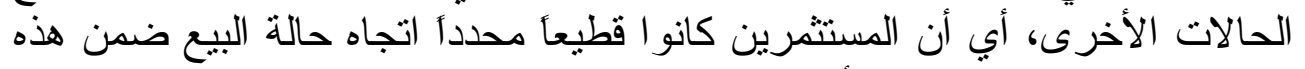

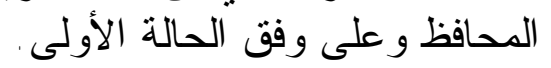




\section{ثانياً - العدوى المالية}

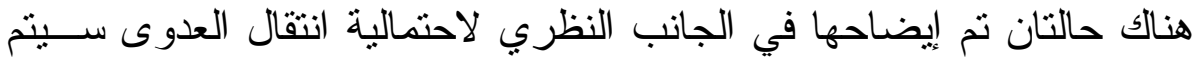

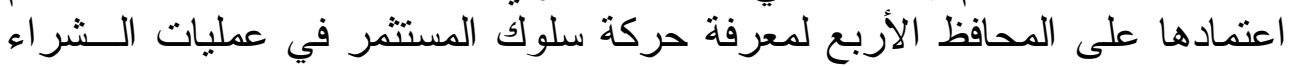

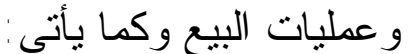

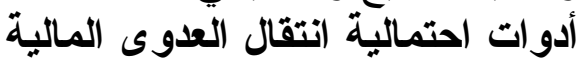

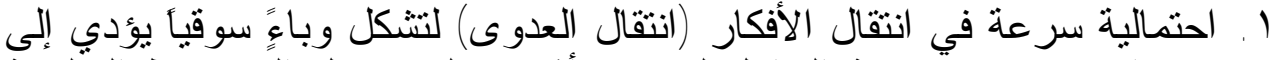

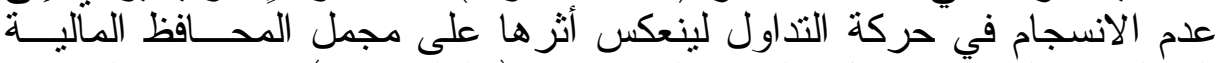

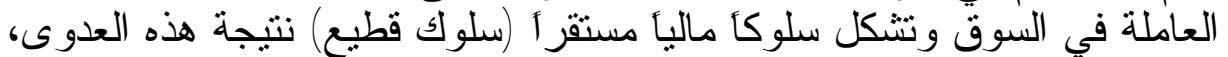
وتبقى في فكر المستثمر بشكل صدمة مالية وكما في الصيغة الرياضية الآتية : $\mathrm{E}\left(\mathrm{V}^{\mathrm{A}} \backslash H_{t}\right)-\mathrm{gE}\left(\mathrm{V}^{\mathrm{A}} \backslash H_{t}, \chi^{\mathrm{A}}\right)<0$

$\mathrm{LE}\left(\mathrm{V}^{\mathrm{A}} \backslash H_{t}, \chi^{A}\right)-E\left(V^{A} \backslash H_{t}\right)<0$ for all $\chi^{\mathrm{A}}$

r.. احتمالية انتقال الأفكار بشكل بطيء (انتقال العدوى) لتبقى تحت السيطرة ويبدأ

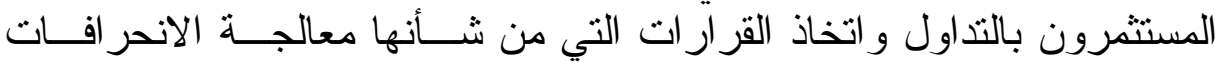

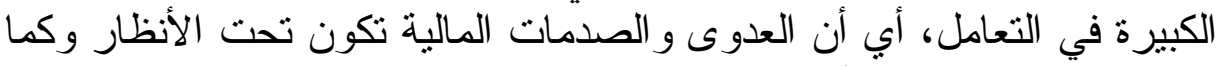

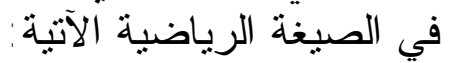
$E\left(V^{B} \backslash H_{t}\right)-g E\left(V^{B} \backslash H_{t}, \chi^{B}\right)\langle 0$ $L E\left(\mathrm{~V}^{\mathrm{B}} \backslash H_{t}, \chi^{B}\right)-E\left(V^{B} \backslash H_{t}\right)\left\langle 0 \quad\right.$ for all $\chi^{\mathrm{B}}$

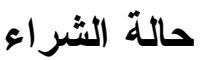

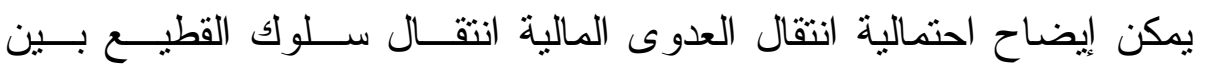
المستثمرين ولحالتين بالتطبيق على المحافظ عينة البحث يعكسها الجدول ^، وكما لئ يأتي:

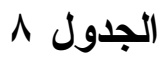

احتمالية انتقال العدوى المالية على سلوك المستثمر (سلوك القطيع) لحالات

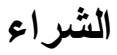

\begin{tabular}{|c|c|c|c|c|c|c|}
\hline St.d & Mean & مؤشثر الأسهة & النمو الآدفاعي & الألأسهية & أشمريكية & \\
\hline 12. & 37.9 & 51.2 & 22.6 & 44.3 & 33.6 & الأولى \\
\hline 1.47 & 62.7 & 64.5 & 609 & 63.0 & 62.6 & \\
\hline
\end{tabular}

يلاحظ من الجدول ^ احتمالية انتقال الأفكار بشكل بطيء (انتقال العـدوى)

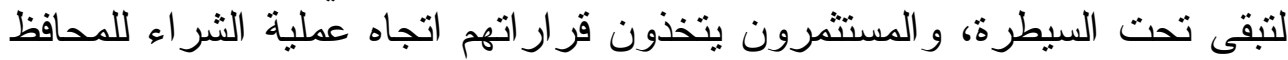

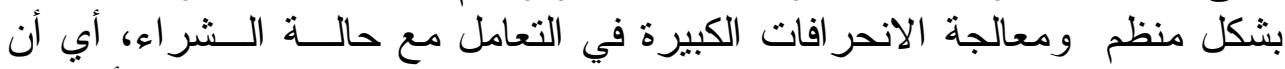

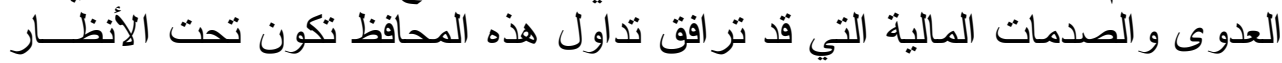

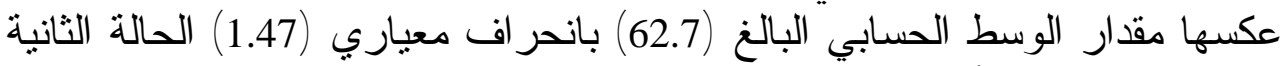

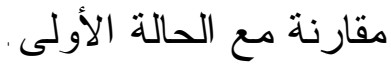


يمكن ملاحظة احتمالية انتقال العدوى المالية لحالات البيع المر افقة للمحــافظ

\section{حالة البيع} المالية قيد الدر اسة عكسها الجدول ^ملية وكما يأني:

\section{الجدول المبول}

احتمالية انتقال العدوى المالية على سلوك المستثمر (سلوك القطيع) لحالات البيع

\begin{tabular}{|c|c|c|c|c|c|c|}
\hline St.d & Mean & مؤشر الأسهرة & الالامريكاعي & الأمريكية & أشمايكا & \\
\hline 22.5 & 60.4 & 87.3 & 33.5 & 66.7 & 54.3 & الأولى \\
\hline 0.35 & 77.0 & 76.7 & 77.0 & 76.8 & 77.5 & الثانية \\
\hline
\end{tabular}

يلاحظ من الجدول ^ م احتمالية انتقال الأفكار بشكل بطيء (انتقــال العـدوى)

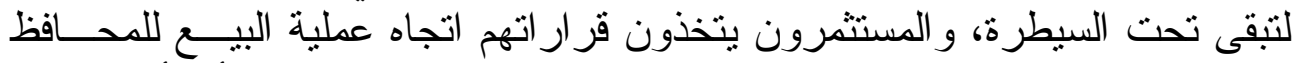

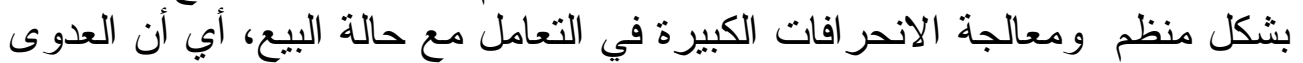

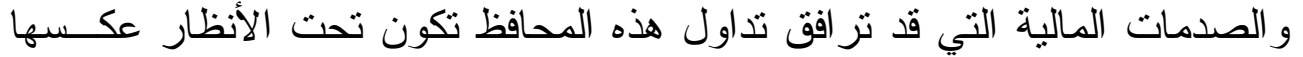
مقدار الوسط الحسابي البالغ (77.0) بانحر اف معياري (0.35) الحالة الثانية مقارنة

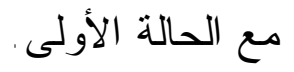

\section{الاستنتاجات و المقترحات \\ الاستنتاجات}

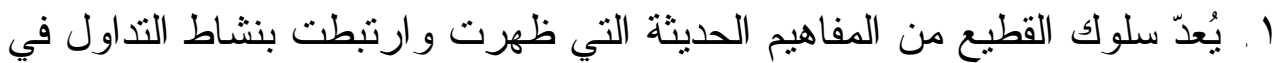

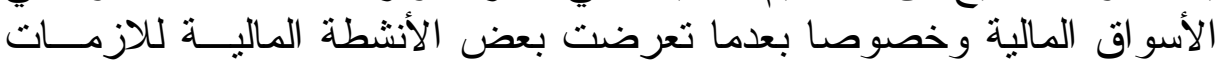

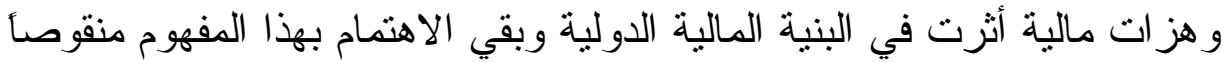
وفي الساحة العربية بحالتنيه النظرية و التطبية النيقية.

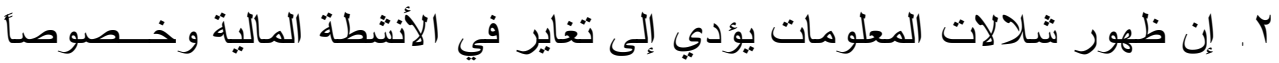

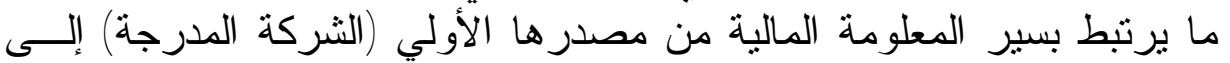

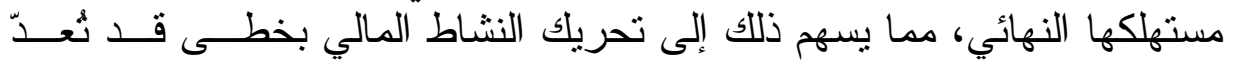

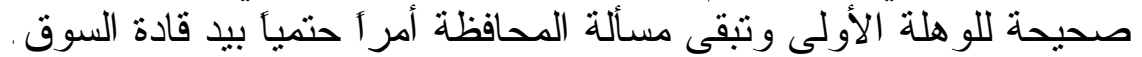

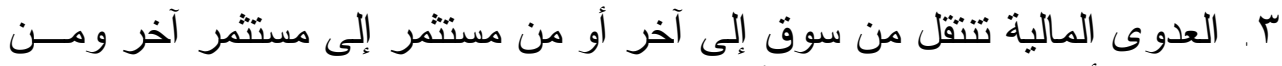

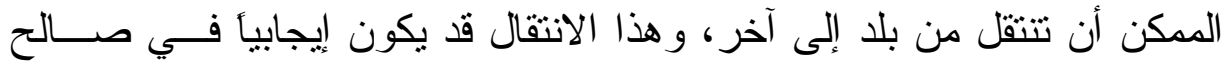

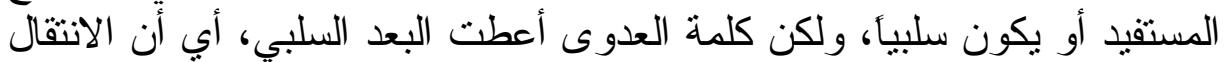

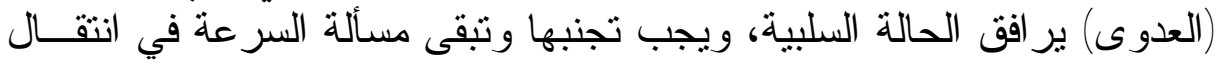

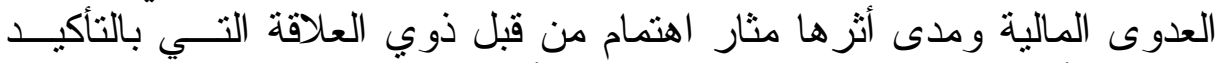

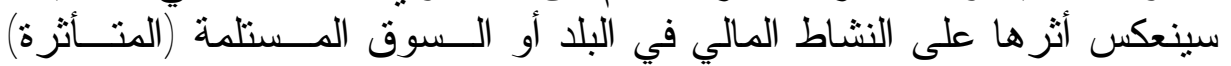

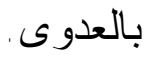


ع . تم الاعتماد على عينة من محافظ مالية مدرجة في سوق السعودية المالية التي

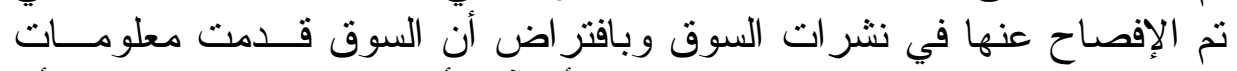

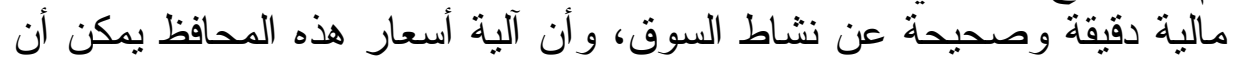

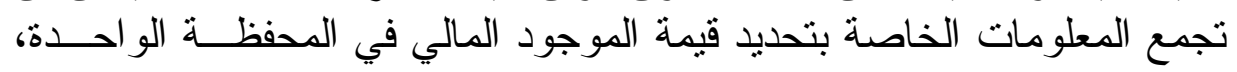

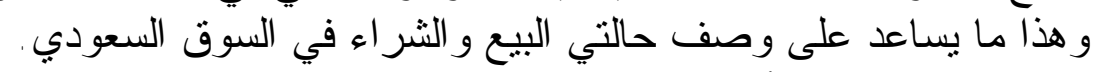

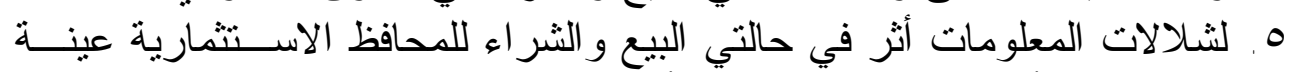

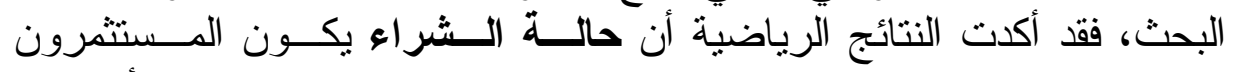

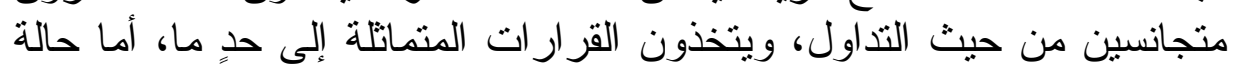

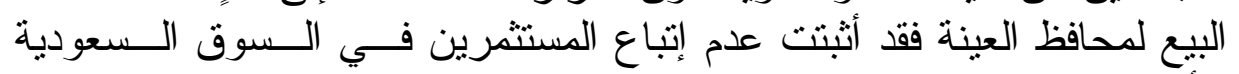

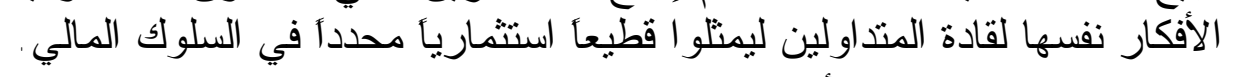

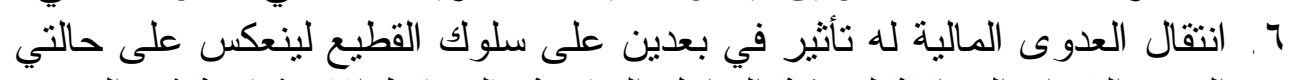

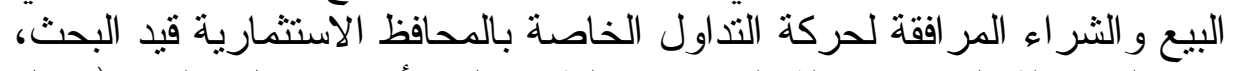

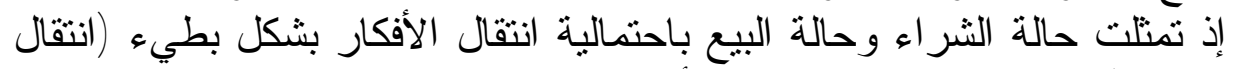

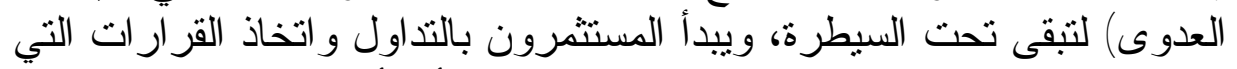

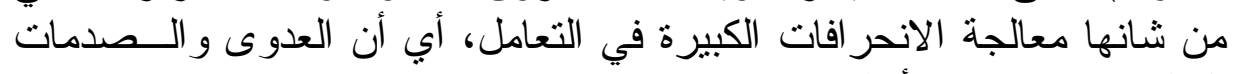

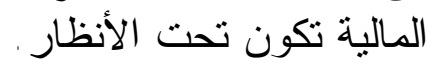

إن تز ايد الكو ارث و الأزمات المالية في مطلع القرن الحادي و العشرين يمثـلـل المقترحات

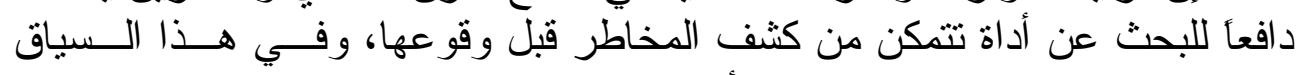

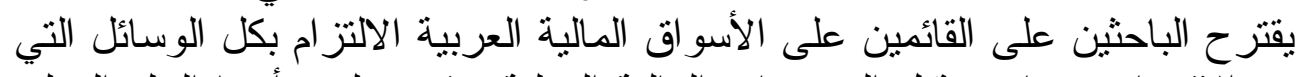

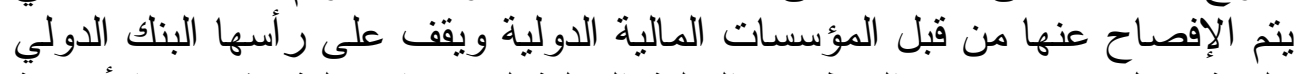

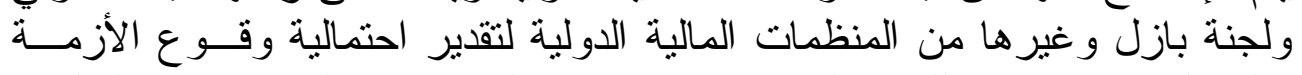

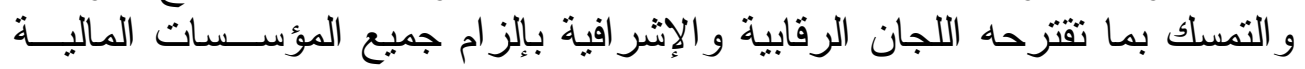

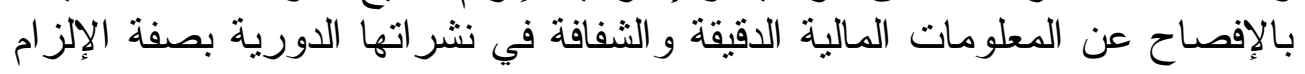

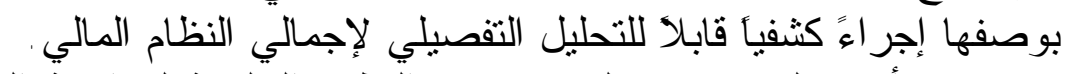

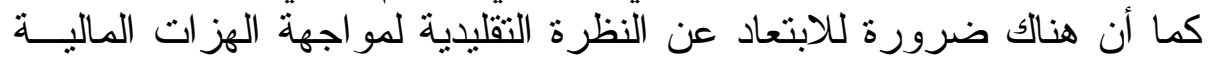

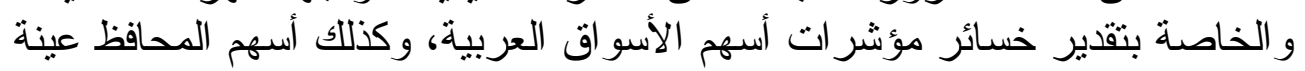

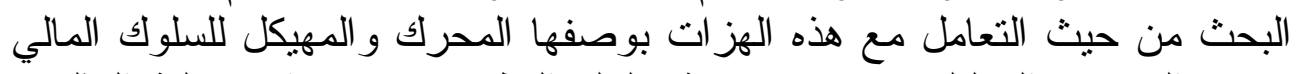

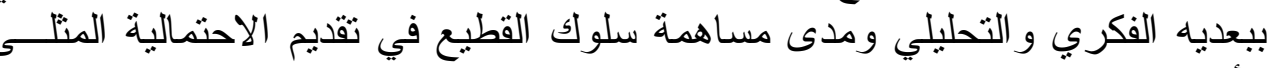
لتأثير ات شلالات المعلومات و العدوى المالية ضمن النشاط المالي. 


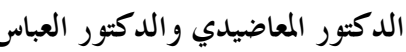

1. A. Devenow and I. Welch.2000,Rational herding in financial economics ,European Economic Review, Vol. 40.

2. Bannerjee, A., 1992, A simple model of herd behavior. Quarterly Journal of Economics 107.

3. Bannerjee, A.,1993, The Economics of Rumours. Review of Economic Studies 60.

4. Bikhchandani, S., D. Hirshleifer \& I. Welch, 1992, A theory of fads, fashion, custom and cultural changes as informational cascades, Journal of Political Economy 100.

5. Chakraborty A. and B. Yilmaz,2000,Informed Manipulation, Wharton School, White Center for Financial Research Working Paper.

6. D.S. Scharfstein and J.C. Stein.2005, Herd behavior and investment, American Economic Review, Vol. 80.

7. Dungey, M., Fry, R.A., Gonzalez-Hermisillo, B. and Martin, V.L. 2002.,International Contagion Effects from the Russian Crisis and the LTCM Near-Collapse ,IMF Working Paper WP/02/74.

8. Dungey, M., Fry, R.A., Gonzalez-Hermisillo, B. and Martin, V.L. 2003, Empirical Modelling of Contagion: A Review of Methodologies, mimeo, ANU and CERF.

9. Fama, E.F. 2005 ,The Behavior of Stock market Prices, Journal of Business, 38.

10. Favero, C.A. and Giavazzi, F., 2002, Is the International Propagation of Financial Shocks Non-Linear? Evidence from the ERM, Journal of International Economics 51.

11. Forbes, K. and Rigobon, R.2001, Measuring Contagion: Conceptual and Empirical Issues, in Claessens, S. and Forbes, K. (eds.), International Financial Contagion, Kluwer Academic Publishers.

12. Gerlach, S. and Smets, F. 1995,Contagious Speculative Attacks, European Journal of Political Economy 11.

13. Goldstein 1998, Contagion and Trade: Why Are Currency Crisis Regional, Journal of International Money and Finance, V. 18.

14. Hirshleifer, David and Siew Hong Teoh, 2003 ,Herd Behavior and Cascading in Capital Markets: a Review and Synthesis, European Financial Management, 9 .

15. International Banking,2004, Financial Contagion Spillovers Through Banking Centers, in the hand book of risk management and analysis,

16. Ioannides, Y.M. 2003, Trading uncertainty and market form, International Economic review, 31.

17. Kaminsky, G.L. and Reinhart, C.M.,2000, On Crises, Contagion and Confusion, Journal of International Economics 51.

18. Lowell, R., Y.-C. Park, and S. Claessens,1998,Contagion: How it spreads and how it can be stopped?, unpublished paper, MIT, Cambridge, Ma.

19. Lux, T., 1998, The socio-economic dynamics of speculative markets. Journal of Economic Behavior and Organization 33.

20. Marco Cipriani and Antonio Guarino,2003, Herd Behavior and Contagion in Financial Markets, Working Paper.

21. Marco Cipriani,\&,Antonio Guarino,2003, Herd Behavior and Contagion in Financial Markets, Department of Economics, George Washington University.

22. Mardi Dungey\& Demosthenes Tambakis,2000,Financial Contagion:What do we Mean?What do we Know?, Working paper, university of Cambridge.

23. Orl'ean, A., 1995, Bayesian interactions and collective dynamics of opinion. Journal of Economic Behavior and Organisation 28.

24. Perry \&Lederman,1998, Financial contagion, Journal of Political Economy, forthcoming.

25. Rigobon, R. 2003, On the Measurement of the International Propagation of Shocks: Is the Transmission Stable?, Journal of International Economics, forthcoming. 
26. Scharfstein, D.S. \& J.C. Stein, 1990, Herd Behavior and Investment. American Economic Review 80.

27. Scharfstein, David, and Jeremy Stein.1990, Herd Behavior and Investment, American Economic Review 80.

28. Shiller R., 1989, Market Volatility. Cambridge, MA: MIT Press.

29. Shleifer, A. \& L.H. Summers, Crowds and Prices: Towards a Theory of Inefficient Markets., Working paper 282, University of Chicago Center for Research in Security Prices.

30. Smith, L. and P. Sorensen,2000, Pathological Outcomes of Observational Learning, Econometrica, 68.

31. Topol, R. ,1991, Bubbles and volatility of stock prices: Effect of mimetic contagion. Economic Journal 101.

32. Trueman, B., 1994, Analysts Forecasts and Herding Behavior. Review of Financial Studies 7.

33. Welch, Ivo 1996, Herding Among Security Analysts. Working paper, University of California at Los Angeles.

1.www.tadawul.com.sa

2.www.sandroses.com 